\title{
Endothelial Rap1B mediates T-cell exclusion to promote tumor growth - a novel mechanism underlying vascular immunosuppression
}

3

Running title: Endothelial Rap1B mediates VEGF immunosuppression

Guru Prasad Sharma ${ }^{a}$, Ramoji Kosuru ${ }^{a}$, Sribalaji Lakshmikanthan ${ }^{a}$, Shikan Zheng ${ }^{a}$, Yao Chen ${ }^{\text {a, }}$ b, Robert Burns ${ }^{a}$, Gang Xin ${ }^{\mathrm{a}}$, Weiguo Cui ${ }^{\mathrm{a}, \mathrm{b}}$, W. and Magdalena Chrzanowska ${ }^{\mathrm{a}, \mathrm{c}, \mathrm{d}}$.

${ }^{a}$ Blood Research Institute, Versiti, Milwaukee, Wisconsin

${ }^{b}$ Department of Microbiology and Immunology, Medical College of Wisconsin, Milwaukee, Wisconsin

'Department of Pharmacology and Toxicology, Medical College of Wisconsin, Milwaukee, Wisconsin

${ }^{\mathrm{d}}$ Cardiovascular Center, Medical College of Wisconsin, Milwaukee, Wisconsin

Keywords: tumor microenvironment, tumor blood vessels, vascular anergy, small GTPase Rap1, angiogenic signaling

Financial support: This work was funded by NIH grant R01HL111582 (M.C.). W.C. is supported by American Cancer Society Research Scholar Grant. RK is supported by the Director's Fellowship Award at the Blood Research Institute of Versiti, Wisconsin.

\section{Corresponding Author: \\ Magdalena Chrzanowska}

ORCID id: 0000-0003-4182-2126

Blood Research Institute, Versiti, Milwaukee, Wisconsin 53201-2178

Department of Pharmacology and Toxicology, Medical College of Wisconsin, Milwaukee, Wisconsin 53226

tel: 414.937 .3890

email: mchrzanowska@versiti.org

Conflict of interest disclosure: The authors declare no potential conflicts of interest. 


\section{Abstract}

38 Overcoming vascular immunosuppression: lack of endothelial cell (EC) responsiveness to

39 inflammatory stimuli in the proangiogenic environment of tumors, is essential for successful

40 cancer immunotherapy. The mechanisms through which Vascular Endothelial Growth Factor

41 (VEGF) modulates tumor EC response to exclude T cells are not well understood. The goal was

42 to determine the role of EC Rap1B, a small GTPase that positively regulates VEGF-

43 angiogenesis during development, in tumor growth in vivo. Using mouse models of Rap1B

44 deficiency, Rap1B ${ }^{+/-}$and EC-specific Rap1B KO $\left(\right.$Rap1B $\left.^{\mathrm{i}{ }^{\mathrm{EC}}}\right)$ we demonstrate that EC Rap1B

45 restricts tumor growth and angiogenesis. More importantly, EC-specific Rap1B deletion leads to

46 an altered tumor microenvironment with increased recruitment of leukocytes and increased

47 activity of tumor $\mathrm{CD}^{+} \mathrm{T}$ cells. We find that tumor growth, albeit not angiogenesis, is restored in

48 Rap1 $\mathrm{B}^{\mathrm{i} \Delta \mathrm{EC}}$ mice by depleting $\mathrm{CD}^{+} \mathrm{T}$ cells. Mechanistically, global transcriptome analysis

49 indicated upregulation of the tumor cytokine, TNF- $\alpha$, -induced signaling and NFKB

50 transcriptional activity in Rap1B-deficient ECs. Functionally, EC Rap1B deletion led to

51 upregulation of NFKB activity and enhanced Cell Adhesion Molecules (CAMs) expression in

52 TNF- $\alpha$ stimulated ECs. Importantly, CAM expression was upregulated also in tumor ECs from

53 Rap1B ${ }^{i \Delta E C}$ mice, vs. controls. Significantly, deletion of Rap1B abrogated VEGF

54 immunosuppressive downregulation of CAM expression, demonstrating that Rap1B is essential

55 for VEGF-suppressive signaling. Thus, our studies identify a novel endothelial-endogenous

56 mechanism underlying VEGF-dependent desensitization of EC to pro-inflammatory stimuli.

57 Significantly, they identify EC Rap1 as a potential novel vascular target in cancer

58 immunotherapy. 


\section{Introduction}

63 Recent cancer immunotherapies involving immune checkpoint inhibitors and chimeric

64 antigen receptor (CAR)-T cell transfer show promise for cancer treatments. These treatments

65 exploit the complex interactions between cancer cells and host tissue in tumor

66 microenvironment (TME), which determine tumor growth and metastasis. Understanding the

67 mechanisms of the host immune response to the tumor is, therefore, critical to the success of

68 immunotherapy (Hendry et al., 2016).

69 Tumor vasculature is a key component of the TME. In response to hypoxia and

70 proangiogenic cytokines, endothelial cell (EC)-driven angiogenesis gives rise to vessels that

71 supply blood to feed the tumor. Moreover, tumor ECs control the TME by regulating leukocyte

72 trafficking and modulating the immune response. The density of tumor-infiltrating T cells, and, in

73 particular, CD8 ${ }^{+}$cytotoxic T cells, correlates with improved survival in many tumors (Fridman et

74 al., 2012). Thus, the success of adoptive T-cell therapies to treat solid cancers depends on

75 successful homing and infiltration by T-lymphocytes (Ager et al., 2016).

Endothelial cells control leukocyte trafficking by upregulating ligands for T-cell adhesion, among them Cell Adhesion Molecules (CAMs): VCAM-1 and ICAM-1, as a response to the proinflammatory cytokines in the TME (Ley et al., 2007). While essential for leukocyte recruitment, the proangiogenic environment in tumors dampens this response. Clinical data and experimental studies in mice suggest that tumor blood vessels are anergic to inflammatory stimuli and the recruitment of cytotoxic CD8 ${ }^{+}$T cells (Ager et al., 2016; Joyce and Fearon,

82 2015), as demonstrated in a number of tumors, including melanoma (Hendry et al., 2016).

83 Endothelial anergy - lack of responsiveness to inflammatory stimuli (Griffioen et al., 1996) is, in

84 part, due to elevated angiogenic factors. In particular, VEGF-A from various TME components is

85 upregulated in solid tumors (VEGF expression correlates with poor prognosis). VEGF decreases EC responsiveness to proinflammatory cytokines and proinflammatory adhesion receptor expression, suppressing leukocyte recruitment (Piali et al., 1995). Specifically, VEGF blocks TNF-a induced NF-kB required for CAM expression and T-cell infiltration (Huang et al., 2015). This concept is supported by evidence from anti-angiogenic therapies leading to upregulation of adhesion molecules on tumor vasculature and increased leukocyte infiltration (Dirkx et al., 2006; Hendry et al., 2016). Interference with VEGF signaling normalizes tumor

92 vasculature and restores responsiveness of ECs to adoptive T-cell therapy also in melanoma

93 (Shrimali et al., 2010). However, incomplete understanding of the mechanisms through which

94 VEGF modulates tumor EC response to exclude T cells (cytokine-induced CAM expression),

95 constitutes a major obstacle in overcoming immunosuppressive properties of tumor ECs. 
Two closely related isoforms of a ubiquitously expressed small GTPase Rap1, Rap1A and Rap1B, are best known for modulation of adhesive and signaling properties of integrins and cadherins (Boettner and Van Aelst, 2009). In endothelium, Rap1 isoforms are required for vessel stabilization during development, but are not essential for vessel maintenance after birth. Instead, both isoforms are positive regulators of developmental angiogenesis (Carmona et al., 2009; Chrzanowska-Wodnicka et al., 2008; Yan et al., 2008). In particular, Rap1B, the

102 predominant Rap1 isoform in the endothelium, promotes VEGF-induced VEGFR2 activation and

103 signaling and its deficiency impairs VEGF-induced angiogenic responses (Chrzanowska-

104 Wodnicka, 2010). Interestingly, Rap1B is also essential for normal VEGF-induced EC barrier

105 dissolution and its deficiency prevents VEGF-mediated hyperpermeability in a diabetes model in

106 vivo (Lakshmikanthan et al., 2018). Thus, there exist synergy between Rap1 and VEGF

107 signaling. However, the role of Rap1B in tumor vasculature has not been studied and its

108 involvement in mechanisms through which VEGF modulates tumor EC responses is unknown.

In this study our goal was to determine whether endothelial Rap1B regulated tumor growth

110 in vivo. We hypothesized that Rap1B deficiency would lead to impaired tumor growth by

111 restricting angiogenesis. We found that, beyond restriction of vessel growth, endothelial Rap1B

112 deficiency led to increased leukocyte recruitment and leukocyte activation. Unexpectedly,

113 deletion of $\mathrm{CD}^{+} \mathrm{T}$ cells rescued impaired tumor growth in EC-specific Rap1B knockout mice

114 (Rap1B $\left.{ }^{\mathrm{i} \mathrm{EC}}\right)$, without normalizing endothelial cell number. At the molecular level, Rap1B 115 deficiency increased EC responsiveness to TME-associated cytokine, TNFa, leading to 116 increased T-cell adhesion. Transcriptomic analysis indicated the significant upregulation of 117 TNFa signaling pathways and NFKB transcription, including proinflammatory CAM expression.

118 Importantly, CAM expression was upregulated in tumor ECs from Rap1B ${ }^{\mathrm{i} E \mathrm{EC}}$ mice. Strikingly, 119 Rap1-deficiency prevented the VEGF-induced inhibition of ECs' proinflammatory response. Our 120 results demonstrate that Rap1B plays an important role in VEGF modulation of EC response in 121 TME, acting predominantly as a suppressor of proinflammatory response. Our findings also 122 suggest inhibition of endothelial Rap1B signaling as a novel target in overcoming endothelial 123 anergy in tumor therapy.

\section{Materials and Methods}

\section{In vivo mouse tumor model}

127 All mouse procedures were performed according to the protocol approved by Medical College of 128 Wisconsin Institutional Animal Use and Care Committee. Generation of total Rap1B knockout

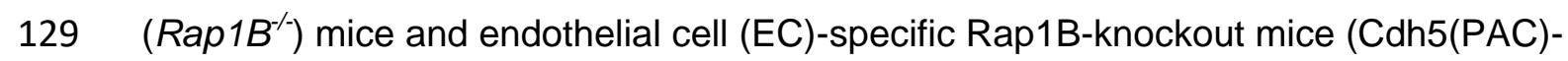


CreERT2 $^{+/ 0}$; Rap1A ${ }^{+/+}$Rap1B $^{\mathrm{f} / \mathrm{f}}$; Rap1B ${ }^{\mathrm{i} \Delta \mathrm{EC}}$ ) has been previously described (ChrzanowskaWodnicka et al., 2005; Lakshmikanthan et al., 2015). Global Rap1B gene heterozygous mice $\left(\operatorname{Rap}_{1 B^{+/-}}\right.$; C57BI/6), in which Rap1B expression is decreased to $\sim 50 \%$ of $\operatorname{Rap}^{B^{+/}}$(WT, control mice), generated by crossing male $\operatorname{Rap}_{1 B^{-/-}}$and female WT mice used for analysis of Rap1Bdeficiency on tumor growth because of high degree of lethality of total Rap1B knockout mice $\left(\operatorname{Rap}_{1 B^{-/}}\right)$. Cdh5-Cre-negative mice, or mice injected with carrier oil only were used as controls for Rap1B ${ }^{\mathrm{i} \Delta \mathrm{EC}}$ mice. Both males and females between the ages of 8 and 20 weeks were used in the study. Melanoma tumors were developed with subcutaneously implanted B16F10 cells $(2 \times$ $10^{5}$ in $100 \mu$ PBS) into the flank area. Tumor growth was monitored using microcallipers every other day for till harvest on day $15^{\text {th }}$, when mice were killed, tumors isolated, weighed and processed for flow cytometry analysis. For CD8 ${ }^{+}-\mathrm{T}$ cell depletion, tumor bearing mice were treated with purified anti-mouse CD8 mAb (clone 53-6.7), or control mAb (clone 2A3) injected itraperitoneally to mice on days 0,2 and 9 (Figure $3 \mathrm{~A}$ ). The efficiency of $\mathrm{CD}^{+} \mathrm{T}$ cell depletion was determined in tumors, blood, bone marrow and spleen by flow cytometry and by hematological analysis.

\section{Cell lines and treatments}

146 All cells lines were obtained from ATCC. B16F10 mouse melanoma cells were cultured in Roswell Park Memorial Institute (RPMI) medium supplemented with $0.1 \mathrm{mM}$ nonessential amino acids, 1 mM sodium pyruvate, 2 mM I-glutamine, 25 mM HEPES, 55 M 2-mercaptoethanol, $10 \%$ FCS and $1 \%$ penicillin-streptomycin (100 U/ml penicillin and $100 \mu \mathrm{g} / \mathrm{ml}$ streptomycin). Human umbilical vein endothelial cells (HUVEC) cultured in endothelial growth medium (EGM-2, Lonza, UK) for fewer than 5 passages were used in all experiments. Human T cell leukemia cell line, Jurkat E6-1, were cultured in RPMI media supplemented with 10\% FCS and 1\% penicillinstreptomycin. All cells were maintained in a humidified $5 \% \mathrm{CO}_{2}$ incubator at $37{ }^{\circ} \mathrm{C} .40-50 \%$ confluent HUVEC monolayers were transfected with 50nM Rap1B siGENOME siRNA pool or with non-targeting siRNA pool (Dharmacon) for 6h in OPTIMEM, and cultured for an additional 30 hours in a complete EBM culture medium. Knockdown efficiency was assessed by Western

157 blotting. For T-cell adhesion assay, RNA sequencing and analysis of CAM expression, siRap1B 158 or siControl-transfected HUVECs were treated with 50nM TNF- $\alpha$ (2\% FBS EBM basal medium) 159 for $12 \mathrm{hrs}$, prior to lysis as described below. For analysis of VEGF-induced suppression of CAM 160 expression, cells were simultaneously treated with $50 \mathrm{ng} / \mathrm{ml} \mathrm{VEGF}$, as previously described 161 (Huang et al., 2015). 


\section{Tumor cell analysis by flow cytometry}

164 Single-cell suspensions of tumors and peripheral organs were prepared in flow cytometry 165 staining buffer (2\% FCS + 1 mM EDTA in PBS), as follows. Tumors were digested in RPMI 1661640 (Lonza) supplemented with $0.6 \mathrm{mg} \mathrm{ml}^{-1}$ collagenase type I (Worthington 4196), $0.1 \mathrm{mg}$ $167 \mathrm{ml}^{-1}$ Type IV bovine pancreatic DNase (Sigma-Aldrich) and $1 \mathrm{M} \mathrm{MgCl}_{2}$ (Sigma) for $45 \mathrm{~min}$ at 37

$168{ }^{\circ} \mathrm{C}$, passed through a $70 \mu \mathrm{m}$ cell strainer and subjected to red blood cell lysis and filtration. A 169 single-cell suspension of the spleen was obtained by tissue mincing in staining buffer. Bone 170 Marrow (BM) cells were isolated by flushing femur and tibia bones in staining buffer and filtering

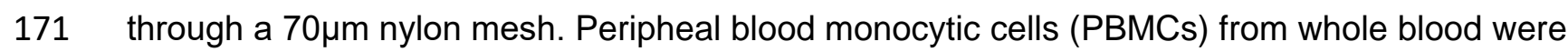
172 isolated by Histopaque gradient method. RBCs were removed using ACK lysis buffer (Lonza).

173 The equal number of cells for each sample were stained with specific directly conjugated 174 monoclonal antibodies (Supplemental Table 1), as previously described (Xin et al., 2020).

175 Controls were stained with IgG isotype-matched control mAbs. 7-AAD dye (Sigma) was used to 176 differentiate live and dead cells. Intracellular granzyme B and INF $\gamma$ staining was performed in 177 cells that had fixed and permeabilized in Flow Cytometry Fixation and Permeabilization Buffers 178 (Catalog numbers FC004, FC005, R\&D systems) following manufacturer's protocol. Stained 179 samples were analyzed on an LSR II flow cytometer (BD Biosciences) or MACSQuant Analyzer 18010 (Miltenyi). The compensation was set up for all the colors used in the experiment. Data were 181 analyzed with the FlowJo software (FlowJo LLC, version 10.0.7). Cellular debris and doublets 182 were removed using viability dye and FSC-A FSC-H gating.

\section{RNA sequencing}

184 siRap1B- or siControl-transfected HUVECs, cultured in growth media (EGM-2, Lonza) were 185 treated with TNF- $\alpha$ for 12 hours. For each biological replicate RNA was extracted from $3 \times 10^{5}$ 186 cells grown in parallel dishes using TRIzol ${ }^{\mathrm{TM}}$ reagent. RNA quantity and quality were assessed 187 by Agilent high sensitivity RNA-Tape Station. RNA-seq libraries were prepared using a modified 188 SMART-Seq2 protocol (Picelli et al., 2014) and sequenced on Illumina NextSeq 500 sequencer 189 using a high-output V2 75 cycle kit (Illumina) in 37 bp paired-end mode. Reads were pseudo190 aligned to the human transcriptome (Ensembl GRCh38 release 102) and expression was 191 quantified using Salmon v1.3.0 (Patro et al., 2017). DESeq2 v 1.26.0 Wald tests were used to 192 determine whether gene expression fold changes were significantly different from zero (Love et 193 al., 2014). For heatmap visualization, data were transformed using the regularized logarithmic 194 transformation (Love et al., 2014). Pre-ranked gene set enrichment analyses (GSEA) were 195 conducted using DESeq2 shrunken fold-changes and fgsea v1.12.0. The KEGG (Ogata et al., 
1999), Reactome (Fabregat et al., 2018) and MSigDB C3:TFT (transcription factor targets) (Liberzon et al., 2011) databases were used for GSEA (Subramanian et al., 2005). The Benjamini-Hochberg method was used to adjust p-values for false-discovery in both differential expression and GSEA analysis (Benjamini and Hochberg, 1995). Data were deposited within NCBI GEO, Accession ID: GSE186046.

\section{NFKB activity assay}

202 HUVECs were plated onto 6-well plates at a density of $5 \times 10^{5}$ cells/well and transfected with 50

203 nM Rap1B siGENOME siRNA pool or with non-targeting siRNA pool (Dharmacon) for $6 \mathrm{hr}$ in

204 OPTIMEM, and cultured for an additional $18 \mathrm{hr}$ in a complete EBM culture medium. After $24 \mathrm{hr}$,

205 siControl and siRap1B cells were infected with NFKB reporter construct pNL3.2.NFKB-

206 RE[NlucP/NF-kB-RE/Hygro] Vector (Promega) using LipofectAMINE-2000, according to the

207 manufacturer's protocol. pNL3.2.CMV Vector (Promega) was used as a negative control for 208 experiments to measure regulated changes in NanoLuc® luciferase expression levels. After a

209 total of $36 \mathrm{hr}$ transfection, cells were trypsinized and seeded in 96-well plates at a density of 3 or $2105 \times 10^{3}$ cells/well and cultured overnight in a complete EBM culture medium. Following day, cells 211 were treated with TNF- $\alpha(20 \mathrm{ng} / \mathrm{ml})$ or vehicle (PBS) for $5 \mathrm{hrs}$. Luciferase activity was measured 212 using the Nano-Glo® Luciferase Assay System (Promega) with an EnSpire Multimode Plate 213 Reader (PerkinElmer), and normalized to cell number. A representative of three independent 214 experiments, each performed in sextuplicate, is depicted as mean fold induction vs. non215 stimulated cells (PBS) (Gu et al., 2016; Seigner et al., 2019).

\section{Adhesion assay}

217 For quantitative assessment of T-cell adhesion to activated endothelium, we adapted previously 218 published protocol (Wilhelmsen et al., 2013). Briefly, siRap1B or siControl-transfected HUVEC 219 monolayers were treated with 50nM TNF-a (2\% FBS EBM basal medium) for $12 \mathrm{hrs.} \mathrm{Jurkat} \mathrm{T}$ 220 cells were washed once with PBS and incubated in serum-free the RPMI-1640 medium with $2215 \mathrm{uM}$ Calcein-AM (BD Biosciences-US) at $37^{\circ} \mathrm{C}$ for 30 minutes. The stained Jurkat $\mathrm{T}$ cells were 222 washed with PBS, and co-cultured with the TNF- $\alpha$-treated HUVECs (1:1) for 45 min at $37^{\circ} \mathrm{C}$.

223 Non-adherent Jurkat cells were removed by washing thrice with PBS. Calcein-AM fuorescence 224 of EC-adhered Jurkat cells was immediately read on a fluorescence plate reader (Perkin Elmer 225 EnSpire 2300) at 495/515 nm. Adhesion efficiency was calculated as a ratio of number of T cells 226 bound per 10,000 cells plated. 


\section{Western blotting}

229 For determination of CAM expression, siRap1B or siControl-transfected HUVECs were treated 230 with 50nM TNF- $\alpha$ (2\% FBS EBM basal medium) for $12 \mathrm{hrs}$. Following completion of adhesion 231 assay, cells were lysed in RIPA cell lysis buffer (100mM Tris-HCl buffer (pH 7.4), 0.150M NaCl, $2320.001 \mathrm{M}$ EDTA, 1\% NP-40, 1\% deoxycholic acid $0.1 \%$ SDS) with $2 \mathrm{mM}$ sodium orthovanadate 233 and $1 \mathrm{X}$ protease/ phosphatase inhibitor cocktail. Cell lysates were clarified by centrifugation and 234 protein concentration was determined PierceTMBCA protein assay kit (Thermo Scientific).

235 Samples containing equal amount of protein were resolved on 4-12\% gradient SDS-PAGE gels 236 and transferred to PVDF membranes. PVDF membrane was blocked in 5\% skim milk/(PBS and $2370.05 \%$ Tween 20 ) for 1 hour at RT and probed with primary antibodies against VCAM-1 (Rabbit 238 mAb \#13662) and Rap1 (Rabbit mAb \#2399), both Cell Signaling Technology), and $\beta$-actin (C4: sc-47778, Santa Cruz Biotechnology) overnight at $4^{0} \mathrm{C}$. Membranes were washed and incubated with horseradish peroxidase (HRP)-conjugated goat-anti-rabbit or donkey-anti mouse secondary antibodies for $1 \mathrm{~h}$ at room temperature followed by chemiluminescence detection using ECL substrate (Pierce) and imaged using Amersham Imager 600 (GE Healthcare). Densitometric band intensity was determined using Amersham Imager 600 analysis software.

\section{Statistical analysis}

Sample sizes were calculated based on variability in our and others' previous studies. Animals were assigned to specific experimental groups without bias. When possible, subject randomization was achieved by distributing experimental groups across multiple cages and litters, as well as blinding during data collection and analysis to remove experimenter's bias. Graphs were generated and statistical analyses performed using GraphPad Prism version 9 (GraphPad Software). Graphs were represented as mean values and standard error of mean (S.E.M.). Student's t-test with Welch's correction was used to measure statistical significance between groups. For comparisons of more than two groups, one-way analysis of variance (ANOVA) with Tukey's multiple comparisons post hoc test was used. * $p<0.05$; ${ }^{* *} p<0.01$; ${ }^{* * *}$

\section{Results}


261 size was monitored until harvested for analysis on day 15 (Figure 1A). The tumor size was

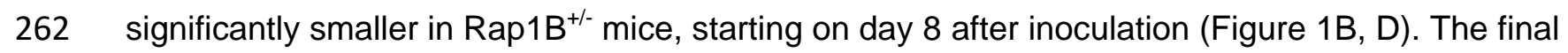

263 tumor weight was also decreased in Rap1B ${ }^{+/-}$mice compared to the wild-type control mice

264 (Figure 1C). To determine the extent of endothelial Rap1B contribution to tumor growth, we

265 examined melanoma growth in EC-specific Rap1B knockout (Rap1B ${ }^{\mathrm{i} E \mathrm{EC}}$ ) and Cdh5-Cre-

266 negative control mice. Similar to total Rap1B depletion, endothelial deletion of Rap1B led to

267 decreased tumor growth (Figure 1E) and decreased final weight and size of tumors (Figure 1F,

268 G). Thus, these results suggest that the endothelial Rap1B significantly contributes to tumor 269 growth.

270 Rap1B positively regulates developmental angiogenesis by promoting EC migration and

271 proliferation (Carmona et al., 2009; Chrzanowska-Wodnicka et al., 2008). Thus, we next

272 examined whether EC Rap1B-deficiency impaired tumor growth by decreasing

273 neovascularization of tumors. Tumors were excised, digested with collagenase-dispase and

274 endothelial compartment was quantitatively assessed in CD31 (PECAM-1)-positive and CD45-

275 negative stained cells by flow cytometry (Figure 1 - figure supplement $1 \mathrm{~A}, \mathrm{~B})$. We found

276 significantly decreased number of ECs/ per tumor weights in tumors from Rap $1 \mathrm{~B}^{\mathrm{i} \mathrm{EC}}$ mice,

277 compared to control mice (Figure 2A). A similar result was obtained in tumors from Rap1B ${ }^{+-}$vs. $^{2}$

278 control mice (Figure 1 - figure supplement 1C). Endothelial identity of the CD31-positive cells

279 was further examined by immunohistochemistry in the tumor (Figure 1 - figure supplement 1D).

280 Similar to the flow cytometry results, there was a significant decrease in CD31-positive cells in

281 vascularized area in the tumor sections from Rap1B-deficient mice (Figure 1 - figure

282 supplement 1E). These findings indicate that Rap1B-deficiency leads to impaired tumor

283 endothelial cell endowment.

\section{Endothelial Rap1B deletion leads to increased T-cell infiltration and adhesion to ECs.}

285 Tumor ECs-driven angiogenesis supports tumor growth by providing blood flow to the ischemic

286 tissue. Moreover, tumor ECs actively control leukocyte infiltration and activation states. To

287 determine if the reduced tumor growth in Rap1B ${ }^{i \Delta E C}$ mice is due to impaired angiogenesis or

288 another aspect of endothelial function altered in the absence of Rap1B, we quantitatively

289 characterized immunce cells from TME in control and Rap1B ${ }^{\mathrm{i} E \mathrm{EC}}$ mice. Single-cell suspensions

290 from tumors from Rap $1 \mathrm{~B}^{\mathrm{i} \Delta \mathrm{EC}}$ and control mice were stained with lymphoid and myeloid cell

291 markers and examined by flow cytometry (Figure 2 - figure supplement 1A). Interestingly, we

292 found that EC-Rap1B deficiency led to quantitative changes in the TME cellularity (Figure 2 -

293 figure supplement 1B-F). Specifically, the number of infiltrated CD45 ${ }^{+}$leukocytes (Figure 2B), 
294 and in particular, $\mathrm{CD}^{+}$(Figure 2C) and $\mathrm{CD}^{+}$(Figure 2D) T cells were increased in tumors from 295 Rap1B $^{\mathrm{i} E \mathrm{EC}}$ mice. To assess the effect of EC Rap1 deletion on CD45 activation, we examined 296 surface expression of CD44, a cell-surface glycoprotein involved in cell-call interactions and a 297 marker of T cell activation (Graham et al., 2007) in Rap1B ${ }^{i \Delta E C}$ and control tumors. We found 298 CD44 expression was significantly upregulated in $\mathrm{CD}^{+}$(Figure 2E) and CD8 ${ }^{+}$T-cells (Figure $2992 \mathrm{~F})$ from Rap1B ${ }^{i \Delta E C}$ mice. To further assess the level of T-cell activation, we examined 300 intracellular expression of T-cell activation marker granzyme B (GrB) (Kelso et al., 2002).

301 Consistently with increased T cell activation, we found increased number of $\mathrm{GrB}^{+} \mathrm{CD}^{+} \mathrm{T}$ cells in 302 tumors from Rap1B ${ }^{i \Delta E C}$, vs. control mice (Figure 3G, H). Thus, EC-specific Rap1B knockout 303 leads to decreased ECs in tumors, but increased leukocyte infiltration and increased leukocyte 304 activity.

\section{Depletion of $\mathrm{CD8}^{+} \mathrm{T}$ cells rescues tumor growth in Rap1B ${ }^{\mathrm{i} \Delta \mathrm{EC}}$ mice}

306 Increased presence of $\mathrm{CD}^{+}$cytotoxic T cells is associated with reduced tumor growth (Ager et 307 al., 2016; Joyce and Fearon, 2015). Our results showing increased leukocyte activation and 308 recruitment to tumors in Rap1B ${ }^{\mathrm{i} \Delta \mathrm{EC}}$ mice suggested endothelial Rap1B might control tumor growth by restricting $\mathrm{CD}^{+} \mathrm{T}$ cell recruitment and activation. To determine if increased CD8 ${ }^{+}-\mathrm{T}$ cell activity/infiltration was responsible for suppressed tumor growth in Rap $1 \mathrm{~B}^{\mathrm{i} \mathrm{EC}}$ mice, we examined the effect of CD8 ${ }^{+}$T-cell depletion in vivo on tumor growth and TME cellularity in Rap1B $^{\mathrm{i} E \mathrm{EC}}$ and control mice (Figure $\left.3 \mathrm{~A}\right)$. Injection of anti-CD8 $\alpha$ monoclonal antibody (mAb), successfully depleted CD8 ${ }^{+} \mathrm{T}$ cells (Figure 3B), but not CD4 ${ }^{+} \mathrm{T}$ cells (Figure 3 - figure supplement $1 \mathrm{~A})$ in tumors from control and Rap1B ${ }^{\mathrm{i} A \mathrm{EC}}$ mice. $C D 8^{+} \mathrm{T}$ cells were also depleted in other tissue compartments (blood, spleen and bone marrow, Figure 3 - figure supplement 2).

317 Figure 3 - figure supplement 3). Interestingly, we found that the anti-CD8 $\alpha$ Ab treatment did not 318 lead to decreased tumor growth in control mice, compared to mice treated with isotype control $319 \mathrm{mAb}$ (Figure $3 \mathrm{C}$ ). This further supports the view that in endothelial Rap1 restricts CD8 ${ }^{+} \mathrm{T}$ cells' 320 effector function and tissue homing in this aggressive melanoma mouse model. In contrast, anti$321 \mathrm{CD} 8 \alpha \mathrm{mAb}$ injection restored tumor growth in Rap1B ${ }^{\mathrm{i} E \mathrm{EC}}$ mice to the level of control mice (Fig.

$3223 \mathrm{C}$, Figure 3 - figure supplement 4).

323 We considered a possibility that restored tumor growth in Rap1B ${ }^{\mathrm{i} \triangle \mathrm{EC}}$ mice upon depletion of $324 \mathrm{CD}^{+} \mathrm{T}$ cell may be via increased angiogenesis (increased EC endowment) rather than altering 325 of $\mathrm{CD}^{+} \mathrm{T}$ cell -EC interactions. To this end, we examined EC endowment in tumors from 326 control and Rap1B ${ }^{i \Delta E C}$ mice (Figure 3D). Although CD8 ${ }^{+}$T-cell depletion did not retard tumor 
327 growth in normal mice, it resulted in a significant decrease in the number of tumor ECs,

328 compared to isotype control mAb-injected mice (Figure 3E). This suggests that in control

329 tumors, EC number is not a tumor growth-limiting factor. Interestingly, depletion of CD8 ${ }^{+} \mathrm{T}$ cells

330 lead to a small, but significant elevation of ECs numbers in tumors in Rap1B ${ }^{i \mathrm{EC}}$ mice (Figure

$3313 E$ ), albeit to a level lower than in WT IgG controls. These results show that restored tumor

332 growth in Rap1B ${ }^{\mathrm{i} \Delta \mathrm{EC}}$ mice is not likely due to improved angiogenesis, but rather inhibition of

333 increased $\mathrm{CD}^{+} \mathrm{T}$ cell activity upon deletion of Rap1B from endothelium.

\section{Rap1B suppresses TNFa-induced NFKB transcription and signaling.}

335 To gain insights into the mechanism through which Rap1B regulates the observed increased

336 leukocyte recruitment and activity, we analyzed the global effects of the TME-associated

337 cytokine, TNF- $\alpha$ treatment on gene expression in siRap1B and siControl ECs by bulk RNA

338 sequencing. Principle component and differential gene expression analyses showed that

339 siRap1B ECs exhibited a distinct transcriptional profile compared to siControl ECs (Figure 4 -

340 figure supplement 1A, B). To assess the TNF- $\alpha$-induced changes in ECs upon Rap1B

341 knockdown, we conducted gene set enrichment analysis (GSEA) using gene sets from the

342 Reactome database. This analysis revealed upregulation of genes in the TNF- $\alpha$ signaling

343 pathway in siRap1B ECs (Figure 4A, B). Furthermore, the transcriptional profile was consistent

344 with upregulation of NFKB transcriptional activity in siRap1B cells (Figure 4C, D and Figure 4 -

345 figure supplement 1C, D). To examine the effect of Rap1B deletion on NFKB activity in ECs,

346 siControl and siRap1B HUVECs were transfected with a NFKB-driven luciferase reporter

347 plasmid or a control, empty plasmid, and emitted luminescence was measured after $5 \mathrm{~h}$ cell

348 exposure to TNF- $\alpha(20 \mathrm{ng} / \mathrm{ml})$. TNF- $\alpha$ induced a modest, but significant luminescence increase

349 in siControl ECs, vs. PBS (Figure 4E). Strikingly, TNF- $\alpha$ induced luminescence was significantly

350 higher in siRap1B ECs (Figure 4E). Consistently with increased NFKB activity, GSEA revealed

351 upregulation of NFKB targets (Figure 4F).

$352 \quad$ Notably, among NFKB-regulated genes upregulated in siRap1B ECs were

353 proinflammatory Cell Adhesion Molecules (CAM)s; ICAM-1 and VCAM-1 (Figures 4B and F,

354 asterisks). To validate these RNAseq data, we examined the effect of TNF- $\alpha$ on CAM protein

355 expression in siRap1B and siControl ECs. TNF- $\alpha$ treatment led to a significant upregulation of

356 VCAM-1 (Figure 5A) and ICAM-1 (Figure 5- figure supplement 1A) in control ECs.

357 Interestingly, and consistent with increased transcript expression, TNF- $\alpha$-induced CAM protein

358 expression was significantly enhanced in Rap1B-deficient ECs (Figure 5A, Figure 5- figure

359 supplement 1A). These findings show that in isolated ECs deletion of Rap1B leads to 
upregulation of CAMs via upregulation of NFkB signaling in response to TME cytokine, TNF- $\alpha$. Importantly, we found that, similarly to the in vitro effect, EC-Rap1B deletion mice led to elevated expression of VCAM (Figure 5B, C) and ICAM-1 (Figure 5- figure supplement 1B) in tumor ECs from Rap1B ${ }^{\mathrm{i} \triangle \mathrm{EC}}$ vs. control mice. Thus, both in vitro and in vivo, EC Rap1B restricts CAM expression in response to a TME-associated cytokine.

EC-controlled expression of CAMs on EC surface controls leukocyte infiltration into tumors, by promoting leukocyte adhesion via integrins on leukocytes and CAMs on endothelium. To determine if increased adhesion to Rap1B-deficient endothelium may contribute to increased tumor infiltration, we measured the effect of TNF- $\alpha$ on leukocyte adhesion in Rap1B-deficient and WT ECs (Wilhelmsen et al., 2013) (Figure 5D). A 24-hour treatment with TNF- $\alpha$ led to a significant increase in leukocyte adhesion in control cells (Figure $5 E)$. However, the number of leukocytes adhering to ECs was significantly increased upon Rap1B knockdown (Figure 5E), supporting our hypothesis that deletion of Rap1B in EC promotes EC-leukocyte interactions. In sum, underlying increased T-cell infiltration into Rap1B $^{\mathrm{i} A \mathrm{EC}}$ tumors is elevated EC inflammatory NFkB activation and CAM expression, which leads to increased adhesion and activation of leukocytes.

\section{Endothelial Rap1B mediates immune suppression in the VEGF pathway}

In addition to stimulating EC angiogenic responses, VEGF promotes tumor growth by dampening EC responsiveness to proinflammatory cytokines and proinflammatory adhesion receptor expression, suppressing leukocyte recruitment. Because Rap1B is a positive regulator of VEGF-mediated angiogenic responses (Chrzanowska-Wodnicka, 2010; Lakshmikanthan et al., 2011), we hypothesized Rap1B may mediate VEGF-induced suppression of EC proinflammatory responses. To test this hypothesis, we examined the effect of Rap1B knockdown on VEGF-mediated modulation of VCAM-1 expression. Consistent with previous reports (Huang et al., 2015), TNF-a-induced VCAM-1 expression was largely inhibited in the presence of VEGF (Fig. 5F). Strikingly, this inhibitory effect of VEGF was abolished in siRap1B ECs, where VEGF failed to reduce TNF- $\alpha$-induced VCAM-1 expression (Figure 5F). Therefore, Rap1B is an essential component of the VEGF signaling that modulates EC response to proinflammatory cytokines. Our findings suggest Rap1B may be a key EC signaling component mediating tumor EC anergy (vasosuppression). 


\section{Discussion}

392 Overcoming vascular immunosuppression - reduced EC responsiveness to inflammatory 393 stimuli - is essential for successful cancer immunotherapy. In this manuscript we demonstrate 394 Rap1B is a key EC component restricting endothelial proinflammatory response. We show that 395 EC Rap1B is permissive for tumor growth, as its EC deficiency suppresses tumor growth and 396 angiogenesis. Perhaps more importantly, the deletion of Rap1B leads to altered TME, increased 397 leukocyte recruitment, and, in particular, increased activity of tumor CD8 ${ }^{+} \mathrm{T}$ cells. We find that 398 tumor growth, albeit not angiogenesis, is restored in Rap1 ${ }^{\mathrm{i} \triangle \mathrm{EC}}$ mice by depleting $\mathrm{CD}^{+} \mathrm{T}$ cells. 399 Therefore, the key function of Rap1B in tumor ECs is to control leukocyte, and specifically CD8 ${ }^{+}$ 400 T cell interactions. Mechanistically, we show that Rap1B deletion leads to upregulation of the 401 TNF- $\alpha$ signaling and cytokine-induced NFKB transcriptional activity. Specifically, EC Rap1B 402 restricts proinflammatory cytokine-induced upregulation of CAMs on ECs and EC-leukocyte 403 interactions in vitro and in tumor ECs, in vivo. Importantly, in the proangiogenic environment 404 present in tumors, Rap1B is essential for mediating VEGF-immunosuppressive signaling, as 405 Rap1-deficiency inhibits VEGF-mediated inhibition of CAM expression. Thus, our studies 406 identify a novel EC-endogenous mechanism underlying VEGF-dependent desensitization of 407 ECs to proinflammatory stimuli. Significantly, they identify EC Rap1B as a potential novel 408 vascular adoptive cell therapy target.

Increased angiogenic factors in TME are linked with tumor progression and tumor vasculature has been a target of anti-tumor therapies (Ferrara and Adamis, 2016; Hendry et al.,

411 2016). Anti-angiogenic therapies block vessel growth, normalize vascular permeability and

412 promote the recruitment of pericytes to stabilize blood flow. Importantly, they sensitize anergic

413 tumor endothelial cells to proinflammatory stimuli, induce proinflammatory expression program

414 which promotes tumor-infiltrating T cells, a positive are prognostic for patient outcome in 415 multiple cancers (Fridman et al., 2012). VEGF is the most prominent tumor angiogenic factor 416 and a number of anti-VEGF therapies have been approved for treatment of cancer (Joyce and 417 Fearon, 2015). However, anti-VEGF therapies lead to adverse effects (tumor aggressiveness, 418 increased metastasis (Ebos et al., 2009; Pàez-Ribes et al., 2009). Moreover, while molecular 419 pathways underlying VEGF-induced vessel formation have been intensely investigated, the 420 mechanism through which VEGF modulates immune responses of tumor vessels remains 421 poorly understood.

422 The findings described in this manuscript provide novel molecular insights into the molecular 423 underpinnings of VEGF-induced immunosuppression. Previous studies implicated Rap1B 
424 developmental angiogenesis (Chrzanowska-Wodnicka, 2013) and demonstrated that Rap1B

425 controls multiple aspects of EC angiogenic responses to VEGF (Chrzanowska-Wodnicka,

426 2010). More recent, molecular studies demonstrated Rap1 acts as an upstream, positive

427 regulator of VEGFR2 signaling important for shear stress sensing and NO release from ECs

428 (Lakshmikanthan et al., 2015), and VEGF-induced vascular permeability (Lakshmikanthan et al.,

429 2018). Consistently with that model, EC-Rap1B deficiency attenuates VEGF-induced

430 permeability in vivo and protects from VEGF-induced hyperpermeability in a diabetes model

431 (Lakshmikanthan et al., 2018). Here, we demonstrate, for the first time, to our knowledge, that

432 Rap1 is essential for VEGF-induced inhibition of the proinflammatory response. While the exact

433 molecular mechanisms need to be elucidated, our findings place Rap1B at the crossroads of

434 VEGFR2 and cytokine signaling, essential for control of tumor growth (Fig. 6).

435 An unbiased transcriptomics approach provided a novel, global view of pathways controlled

436 by Rap1B (Figure 4 and Figure 4 - figure supplement 1). The top pathway upregulated in the

437 absence of Rap1B is the NFKB -mediated proinflammatory response. Deletion of Rap1B leads

438 to upregulation of NFKB targets, including CAM receptors, both: in vitro and in tumor ECs in

439 vivo. Interestingly, Rap1B deletion also leads to upregulation of CAMs in a mouse

440 atherosclerosis model (Singh et al., 2021). Additional NFKB proinflammatory targets likely

441 contribute to the increased leukocyte infiltration and leukocyte infiltration in Rap1B ${ }^{\mathrm{i} E \mathrm{EC}}$ tumors,

442 and warrant further investigation. The analysis of Rap1B ${ }^{\mathrm{i} \Delta \mathrm{EC}} \mathrm{TME}$ cellularity revealed that $\mathrm{EC}$

443 Rap1B-deficiency selectively affected other leukocyte populations; in particular the number of

444 some tumor $B$ cells was increased in Rap1B ${ }^{i \mathrm{EC}}$ tumors vs. controls (Figure 2 - figure

445 supplement 1D, E). Future studies will determine whether these effects are primary or

446 secondary. Nonetheless, our findings support Rap1B as a key regulator of EC-leukocyte

447 interactions via a novel mechanism involving suppression of proinflammatory signaling. These

448 results also reveal a new aspect of Rap1 biology in endothelium. Future studies will focus on the

449 mechanisms of transcriptional control by Rap1B and their implications in proinflammatory

450 states.

451 In sum, we identified Rap1B as a novel molecular regulator of EC proinflammatory

452 response, which may lead to new therapeutic approaches to overcome vascular

453 immunosuppression in cancer immunotherapy. 


\section{Figure, figure supplements and figure source data legends}

457 Figure 1. Global and EC-specific Rap1B deletion restricts tumor growth in vivo.

458 (A) A schematic diagram of melanoma induction in global Rap1B-deficient mice, Rap1B ${ }^{+/-}$, or 459 EC-specific Rap1B knockouts, Rap1B ${ }^{i \Delta E C}$. Tumor growth kinetics (B), tumor weight at day 15

460 (C) and representative photographs of melanoma growth (D) in Rap1B ${ }^{+/-}(n=10)$ vs. Rap1B ${ }^{+/+}$ $461(n=10)$ mice. Tumor growth kinetics (E), tumor weights $(\mathbf{F})$ and representative photographs of 462 melanoma growth $(\mathbf{G})$ in $\operatorname{Rap} \mathrm{B}^{\mathrm{i} \triangle \mathrm{EC}}(\mathrm{n}=5)$ vs. Cre-negative control mice $(n=6)$. Data represent 463 mean \pm SEM. * $, \mathrm{P}<0.05^{* *}, \mathrm{P}<0.01{ }^{* * *}, \mathrm{P}<0.001$, Student's $t$ test. Data and statistical 464 outputs are available in Figure 1-source data 1 file.

465 Figure 1-source data 1: relates to panels A-F.

466 Figure 1- figure supplement 1. Reduced CD31+ endothelial cells in Rap1B ${ }^{+/}$tumors. (A). 467 Gating strategy for endothelial cells $\left(\mathrm{CD} 31^{+}\right)$and leukocytes $\left(\mathrm{CD} 45^{+}\right)$using stained single-cell 468 suspension from the harvested tumors. Representative plots from a control tumor are shown. 469 One million events were acquired on BD FACS-diva (LSR II-Green) using single-cell suspension 470 from the harvested tumors. Viable, 7-AAD-negative cells were identified, and cell doublets were 471 discriminated by their SSC and FSC characteristics. Single cells were further gated for 472 leukocytes (CD45 $\left.{ }^{+} \mathrm{CD} 31^{-}\right)$and endothelial cells (CD31 $\left./ \mathrm{CD} 45^{\circ}\right)$. (B) Decreased number of 473 tumor endothelial cells (CD31 $/$ CD45) isolated from Rap1B ${ }^{+/-}$mice vs. control, shown as \% of 474 gated single cells $\left(\mathbf{C}^{*}, \mathrm{P}<0.05\right)$. Data are presented as the mean \pm S.E.M. $\mathrm{n}=5$ mice per 475 group, student's $t$ test. (D) Typical immunofluorescent staining of CD $45^{+}$cells (green) and

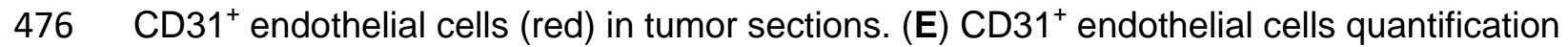
477 demonstrates a significant decrease in ECs in tumor sections in Rap1B ${ }^{+/}$, vs. control group $\left({ }^{*}, \mathrm{P}\right.$ $478<0.05) . \mathrm{n}=3$ mice per group, Student's $t$ test. Data and statistical outputs are available in 479 Figure 1 - figure supplement 1-source data 1 file.

480 Figure 1 - figure supplement 1-source data 1: relates to panels $\mathrm{C}$ and $\mathrm{E}$. Figure 2. Endothelial Rap1B restricts tumor T-cell infiltration. (A-D) Endothelial Rap1Bdeficiency alters TME cellularity. Flow cytometry analysis of single cell suspensions from tumors stained with cell-type specific markers demonstrate decreased endothelial cell numbers $\left(C D 31^{+,} A\right)$, and increased CD45 cells $(B)$ in Rap1B ${ }^{i \Delta E C}(n=5)$ vs. control mice $(n=5)$. Gating strategy shown in Supplementary Fig. S1. CD4 ${ }^{+} \mathrm{T}$ cells (C) and CD8 ${ }^{+} \mathrm{T}$ cells (D) selected as shown in gating scheme in Supplementary Figure S3. (E-H) Elevated T cell activation in 
FACS plots (G) and quantification of median fluorescence intensity, (MFI, $\mathbf{H})$ of intracellular staining for granzyme $B(\mathrm{GrB})$ in tumor $C D 8{ }^{+} T$ cells from Rap1 $\mathrm{B}^{\mathrm{i} \triangle \mathrm{EC}}(\mathrm{n}=8)$ and control mice $(n=5)$. Data represent mean \pm SEM. * $, P<0.05^{* *}, P<0.01$, ${ }^{* * *}, P<0.001$, Student's t-test.

493 Data and statistical outputs are available in Figure 2-source data 1 file.

494 Figure 2-source data 1: relates to panels A-F, H.

495 Figure 2-figure supplement 1. EC-specific Rap1B deletion alters recruitment of tumor496 infiltrating lymphocytes (TIL). (A) Gating and selection of immune cell types from tumor

497 single-cell suspensions. Representative plots from a control tumor are shown. One million 498 events were acquired on BD FACS-diva (LSR II-Green) using single-cell suspension from the

499 harvested tumors. Single cells were used to identify CD45 leukocytes, which were further gated 500 using marker-specific antibodies against NK1.1 (natural killer cells), CD4, CD8 and B220 Bcells. B-F. Quantitation of cell populations: (B) B cells $\left(\mathrm{B} 220^{+}\right),(\mathbf{C})$ natural killer cells $\left(\mathrm{NK} 1.1^{+}\right)$, (D) myeloid cells $\left(\mathrm{CD} 11 \mathrm{~b}^{+}\right),(\mathrm{E})$ monocytes $\left(\mathrm{Ly}_{6 \mathrm{C}^{+}}\right)$and $(\mathbf{F})$ macrophage $\left(\mathrm{F} 4 / 80^{+}\right)$in single-cell suspension of tumors from Rap1B ${ }^{i \Delta E C}$ or control mice. Data are presented as the mean \pm S.E.M. *, $\mathrm{P}<0.05 . \mathrm{n}=5$ mice per group, Student's $t$ test. Data and statistical outputs are available in Figure 2- figure supplement 1-source data 1 file.

Figure 2- figure supplement 1-source data 1: relates to panels B-F.

Figure 3. Depletion of CD8 ${ }^{+} \mathrm{T}$ cells normalizes tumor growth in Rap1B ${ }^{\mathrm{i} \triangle \mathrm{EC}}$ mice. efficient cell depletion in with anti-CD8 antibody or IgG isotype control. (C) Tumor growth kinetics in Rap1B ${ }^{i \mathrm{EC}}$ vs. Cre-negative control treated with anti-CD8 . (D) Gating scheme and quantification of $\mathrm{CD} 31^{+} \mathrm{ECs}(\mathrm{E})$ and $\mathrm{CD} 45^{+}$cells (F). Data are presented as the mean \pm S.E.M

514 ( $n=6$ per group). ${ }^{*}, P<0.05,{ }^{* *}, P<0.01,{ }^{* *}, P<0.001$, Panels $B, C, F$ : one-way ANOVA with

515 Tukey's post hoc test. Panel E: Student's t-test. Data and statistical outputs are available in

516 Figure 3-source data 1 file.

517 Figure 3-source data 1: relates to panels B, C, E and F.

518 Figure 3 - figure supplement 1. Efficiency of CD8 ${ }^{+}$T cell depletion in specific tissue 519 compartments.

520 Peripheral blood cells (A), spleen cells (B) and bone marrow cells (C) were stained with Very 521 CD8 mAb. Flow analysis showing drastic depletion of CD8 ${ }^{+}$cells in all tissue compartment. IgG 522 isotype control has no significant modulation on T cell. Data are presented as the mean \pm 523 S.E.M. ${ }^{* * *}, \mathrm{P}<0.001{ }^{* * * *}, \mathrm{P}<0.0001 . \mathrm{n}=6$ mice per group, one-way ANOVA with Tukey's 
524 multiple comparisons post hoc test. Data and statistical outputs are available in Figure 3 - figure

525 supplement 1-source data 1 file.

526 Figure 3 - figure supplement 1-source data 1: relates to panels A-F.

527 Figure 3 - figure supplement 2. Hematological (CBC) analysis in control and Rap1B ${ }^{\mathrm{i} \triangle E C}$

528 mice after CD8 $^{+}$T cell depletion. Whole blood ( $13 \mu$ l per mouse) was collected into

529 anticoagulant (1:10) using capillary tubes (StatSpin® Microhematocrit Tubes, VWR). The blood

530 samples were immediately analyzed using an automated Hematology blood analyzer (Sysmex

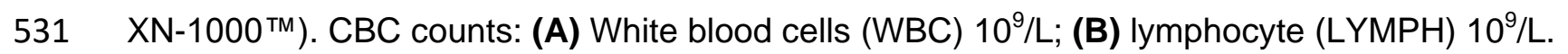

532 (C) Immature (young) RBC fraction, as measured by \% of high fluorescence reticulocyte (HFR),

533 (D) Platelets (PLT) 10 $12 / \mathrm{L}$, (E) Red blood cells (RBC) $10^{12} / \mathrm{L}$, and (F) Neutrophils (NEUT). Data

534 are presented as the mean \pm S.E.M. ${ }^{*}, \mathrm{P}<0.05,{ }^{*}, \mathrm{P}<0.01 . \mathrm{n}=6$ mice per group, one-way

535 ANOVA with Tukey's multiple comparisons post hoc test. Data and statistical outputs are

536 available in Figure 3 - figure supplement 2-source data 1 file.

537 Figure 3 - figure supplement 2-source data 1: relates to panels A-C.

538 Figure 3 - figure supplement 3. Effect of CD8 ${ }^{+}$T-cell depletion on tumor-infiltrating

539 lymphocytes (TIL) in control and Rap1B ${ }^{\mathrm{i} \Delta \mathrm{EC}}$ mice. Immunophenotypic examination showing

540 quantitation of (A) CD4 ${ }^{+}$T cells, (B) B cells $\left(B 220^{+}\right),(C)$ myeloid cells $\left(C D 11 b^{+}\right),(D)$ monocytes

$541\left(\mathrm{Ly} 6 \mathrm{C}^{+}\right),(\mathrm{E})$ neutrophils $\left(\mathrm{Ly}_{6 \mathrm{G}}\right)$ and $(\mathrm{F})$ macrophage $\left(\mathrm{F} 4 / 80^{+}\right)$in Rap1B ${ }^{\mathrm{i} \Delta \mathrm{EC}} /$ control mice treated

542 with either IgG isotope or CD8 mAb. Data are presented as the mean \pm S.E.M. ${ }^{*}, P<0.05,{ }^{* *}, P$

$543<0.01 . n=6$ mice per group, one-way ANOVA with Tukey's multiple comparisons post hoc test.

544 Data and statistical outputs are available in Figure 3-figure supplement 3-source data 1 file.

545 Figure 3 - figure supplement 3-source data 1: relates to panels A-F.

546 Figure 3 - figure supplement 4. Depletion of CD8 ${ }^{+}$T-cells normalizes tumor growth in

547 Rap1B ${ }^{\mathrm{i} \triangle \mathrm{EC}}$ mice. Representative photographs showing pattern of tumor growth in

$548 \mathrm{Rap}^{\mathrm{i}} \mathrm{B}^{\mathrm{\triangle ECC}} /$ control mice treated with either $\lg \mathrm{G}$ isotope or CD8 mAb. (A) lgG isotope has no

549 effect on tumor growth in control group. (B) $\mathrm{CD}^{+} \mathrm{T}$ cell depletion significantly rescued tumor

550 reduction in Rap1 $\mathrm{B}^{\mathrm{i} \Delta \mathrm{EC}}$ mice group.

551

552 Figure 4. Endothelial Rap1B restricts TNF- $\alpha$ induced NFKB activation.

553 Increased TNF- $\alpha$ signaling and NFKB transcription detected by bulk RNA sequencing of TNF- $\alpha-$

554 treated siRap1B and siControl Ecs. (A) Gene set enrichment analysis (GSEA) of genes in TNF-

555 a signaling pathway upregulated in siRap1B vs. siControl. (B) Heatmap of selected genes from

556 TNF- $\alpha$ signaling pathway. (C) GSEA of NFKB signaling pathway. (D) Transcriptional activation

557 of NFKB in siRap1B ECs. (E) TNF- $\alpha$-induced NFKB activity determined by luciferase assay in 
cells transfected with NF-KB reporter construct or a control vector (CMV). Values shown as mean fold change vs. PBS-treated cells. Error bars represent mean $\pm S D(n=6) .{ }^{*}, P<0.05$, ${ }^{* * * *}, \mathrm{P}<0.0005$. One-way ANOVA followed by Tukey's multiple comparisons test. (F) Heatmap of selected genes from NFKB pathway. ( $n=5$ separate EC sets per group). Link to sequence data deposited within NCBI GEO is available in Figure 4-source data 1 file. Data and statistical outputs for panel $\mathrm{E}$ are available in Figure 4-source data 2 file.

564 Figure 4-source data 1: relates to panels $A-D$ and $F$.

565 Figure 4-source data 2: relates to panel E.

\section{Figure 4 - figure supplement 1. Transcriptomic analysis of TNF- $\alpha$-stimulated siControl} and siRap1B ECs. (A) Principal component analysis of samples. (B) Volcano plot of differential gene expression, the top 50 significantly differentially expressed genes are labeled. (C) Gene set enrichment analyses (GSEA) of NFKB target genes. (D) Dot plot of top significantly enriched transcription factors by GSEA $(n=5)$. Link to sequence data deposited within NCBI GEO is available in Figure 4-source data 1 file. signaling. (A) Top: Densitometry of TNFa-induced VCAM-1 expression, normalized to actin, in siControl- or siRap1B- transfected HUVECs. Bottom: representative Western blot. Original images are available in Figure 5-source data 1 file. (B, C) VCAM-1 expression in tumor ECs $\left(\mathrm{CD} 31^{+}\right.$cells): representative flow cytometry histogram $(\mathbf{B})$ and median fluorescence intensity (MFI) (C). $n \geq 5$ mice per group, (D, E) EC-Rap1B deficiency leads to increased leukocyte adhesion in vitro. Representative image (D) and quantification (E) of Calcein-AM-labeled Jurkat cells adhering to siRap1B and siControl ECs following TNF- $\alpha$ treatment 12 hours. Adhesion efficiency is expressed as Jurkat cells bound/10,000 plated. (F) VEGF treatment inhibits TNF- $\alpha$ induced CAM expression in siControl but not in siRap1B ECs. Densitometry (top) and representative Western blot (bottom) are shown. Original images are available in Figure 5source data 2 file. Data shown are mean \pm S.E.M. ${ }^{*}, P<0.05$, ${ }^{* *}, P<0.01,{ }^{* *}, P<0.001$,

585 Panels A, E, F: one-way ANOVA followed by Tukey's multiple comparisons test. Panel C:

586 Student's t-test. Data and statistical outputs are available in Figure 5-source data 3 file.

587 Figure 5-source data 1: original images of Western blots in panel A.

588 Figure 5-source data 2: original images of Western blots in panel F.

589 Figure 5-source data 3: relates to panels A, C, E and F.

590 Figure 5 - figure supplement 1. Elevated ICAM-1 surface expression in Rap1B-deficient

591 tumor ECs and HUVECs. (A) Flow cytometric analysis of ICAM-1 expression on siRap1B and 
592 siControl HUVEC cells. (B) Flow cytometric analysis of ICAM-1 expression on tumor ECs from

593 Rap1 $\mathrm{B}^{\mathrm{i} \triangle \mathrm{EC}}$ and control mice: representative flow cytometry histogram and median fluorescence

594 intensity (MFI) plot (C). Data are presented as the mean \pm S.E.M. ${ }^{* *}, P<0.01$, Student's $t$ test.

595 Data and statistical outputs are available in Figure 5 - figure supplement 1-source data 1 file.

596 Figure 5 - figure supplement 1-source data 1: relates to panels $\mathrm{A}$ and $\mathrm{C}$.

Figure 6. Endothelial Rap1B conveys VEGF suppression of immune reactivity - proposed

599 mechanism. Under normal conditions Rap1 suppresses cytokine-induced CAM expression,

600 limiting T-cell adhesion and recruitment. In proangiogenic conditions of TME, VEGF signaling,

601 mediated by Rap1B, suppresses this endothelial immune response.

602

603

604

605

606

607

608

609 


\section{References}

625

Ager, A., H.A. Watson, S.C. Wehenkel, and R.N. Mohammed. 2016. Homing to solid cancers: A vascular checkpoint in adoptive cell therapy using CAR T-cells. Biochemical Society Transactions. 44:377-385.

Benjamini, Y., and Y. Hochberg. 1995. Controlling the False Discovery Rate: A Practical and Powerful Approach to Multiple Testing. Journal of the Royal Statistical Society. Series B (Methodological). 57:289-300.

Boettner, B., and L. Van Aelst. 2009. Control of cell adhesion dynamics by Rap1 signaling. Current Opinion in Cell Biology. $21: 684-693$.

Carmona, G., S. Gottig, A. Orlandi, J. Scheele, T. Bauerle, M. Jugold, F. Kiessling, R. Henschler, A.M. Zeiher, S. Dimmeler, and E. Chavakis. 2009. Role of the small GTPase Rap1 for integrin activity regulation in endothelial cells and angiogenesis. Blood. 113:488-497.

Chrzanowska-Wodnicka, M. 2010. Regulation of angiogenesis by a small GTPase Rap1. Vascular Pharmacology. 53:1-10.

Chrzanowska-Wodnicka, M. 2013. Distinct functions for Rap1 signaling in vascular morphogenesis and dysfunction. Experimental Cell Research. 319:2350-2359.

Chrzanowska-Wodnicka, M., A.E. Kraus, D. Gale, G.C. White, 2nd, and J. Vansluys. 2008. Defective angiogenesis, endothelial migration, proliferation, and MAPK signaling in Rap1b-deficient mice. Blood. 111:2647-2656.

Chrzanowska-Wodnicka, M., S.S. Smyth, S.M. Schoenwaelder, T.H. Fischer, and G.C. White. 2005. Rap $1 b$ is required for normal platelet function and hemostasis in mice. Journal of Clinical Investigation. 115:2296-2296.

Dirkx, A.E.M., M.G.A. Oude Egbrink, K. Castermans, D.W.J. Van Der Schaft, V.L.J.L. Thijssen, R.P.M. Dings, L. Kwee, K.H. Mayo, J. Wagstaff, J.C.A. Bouma-ter Steege, and A.W. Griffioen. 2006. Anti-angiogenesis therapy can overcome endothelial cell anergy and promote leukocyte-endothelium interactions and infiltration in tumors. FASEB Journal. 20:621-630.

Ebos, J.M.L., C.R. Lee, W. Cruz-Munoz, G.A. Bjarnason, J.G. Christensen, and R.S. Kerbel. 2009. Accelerated Metastasis after Short-Term Treatment with a Potent Inhibitor of Tumor Angiogenesis. Cancer Cell. 15:232-239.

Fabregat, A., S. Jupe, L. Matthews, K. Sidiropoulos, M. Gillespie, P. Garapati, R. Haw, B. Jassal, F. Korninger, B. May, M. Milacic, C.D. Roca, K. Rothfels, C. Sevilla, V. Shamovsky, S. Shorser, T. Varusai, G. Viteri, J. Weiser, G. Wu, L. Stein, H. Hermjakob, 

Research. 46:D649-D655.

Ferrara, N., and A.P. Adamis. 2016. Ten years of anti-vascular endothelial growth factor therapy. Nature Reviews Drug Discovery. 15:385-403.

Fridman, W.H., F. Pagès, C. Sauts-Fridman, and J. Galon. 2012. The immune contexture in human tumours: Impact on clinical outcome. Nature Reviews Cancer. 12:298-306.

Graham, V.A., A.L. Marzo, and D.F. Tough. 2007. A role for CD44 in T cell development and function during direct competition between CD44+ and CD44- cells. European Journal of Immunology. 37:925-934.

Griffioen, A.W., C.A. Damen, S. Martinotti, G.H. Blijham, and G. Groenewegen. 1996.

Hendry, S.A., R.H. Farnsworth, B. Solomon, M.G. Achen, S.A. Stacker, and S.B. Fox. 2016. The role of the tumor vasculature in the host immune response: Implications for therapeutic strategies targeting the tumor microenvironment. Frontiers in Immunology. 7.

Huang, H., E. Langenkamp, M. Georganaki, A. Loskog, P.F. Fuchs, L.C. Dieterich, J. Kreuger, and A. Dimberg. 2015. VEGF suppresses T-lymphocyte infiltration in the tumor microenvironment through inhibition of NF-KB-induced endothelial activation. FASEB Journal. 29:227-238.

Joyce, J.A., and D.T. Fearon. 2015. T cell exclusion, immune privilege, and the tumor microenvironment. Science. 348:74-80.

Kelso, A., E.O. Costelloe, B.J. Johnson, P. Groves, K. Buttigieg, and D.R. Fitzpatrick. 2002. The genes for perforin, granzymes $\mathrm{A}-\mathrm{C}$ and IFN- $\gamma$ are differentially expressed in single CD8+ T cells during primary activation. International Immunology. 14:605-613.

Lakshmikanthan, S., M. Sobczak, C. Chun, A. Henschel, J. Dargatz, R. Ramchandran, and M. Chrzanowska-Wodnicka. 2011. Rap1 promotes VEGFR2 activation and angiogenesis by a mechanism involving integrin alphavbeta(3). Blood. 118:2015-2026.

Lakshmikanthan, S., M. Sobczak, S. Li Calzi, L. Shaw, M.B. Grant, and M. ChrzanowskaWodnicka. 2018. Rap1B promotes VEGF-induced endothelial permeability and is required for dynamic regulation of the endothelial barrier. Journal of Cell Science. 131. 
691

692

693

694

695

696

697

698

699

700

701

702

703

704

705

706

707

708

709

710

711

712

713

714

715

716

717

718

719

720

721

722

723

724

Lakshmikanthan, S., X. Zheng, Y. Nishijima, M. Sobczak, A. Szabo, J. Vasquez-Vivar, D.X. Zhang, and M. Chrzanowska-Wodnicka. 2015. Rap1 promotes endothelial mechanosensing complex formation, NO release and normal endothelial function. EMBO Reports. 16:628-637.

Ley, K., C. Laudanna, M.I. Cybulsky, and S. Nourshargh. 2007. Getting to the site of inflammation: The leukocyte adhesion cascade updated. Nat. Rev. Immunol. 7:678-689.

Liberzon, A., A. Subramanian, R. Pinchback, H. Thorvaldsdóttir, P. Tamayo, and J.P. Mesirov. 2011. Molecular signatures database (MSigDB) 3.0. Bioinformatics. 27:1739-1740.

Love, M.I., W. Huber, and S. Anders. 2014. Moderated estimation of fold change and dispersion for RNA-seq data with DESeq2. Genome Biology. 15.

Ogata, H., S. Goto, K. Sato, W. Fujibuchi, H. Bono, and M. Kanehisa. 1999. KEGG: Kyoto encyclopedia of genes and genomes. Nucleic Acids Research. 27:29-34.

Pàez-Ribes, M., E. Allen, J. Hudock, T. Takeda, H. Okuyama, F. Viñals, M. Inoue, G. Bergers, D. Hanahan, and O. Casanovas. 2009. Antiangiogenic Therapy Elicits Malignant Progression of Tumors to Increased Local Invasion and Distant Metastasis. Cancer Cell. 15:220-231.

Patro, R., G. Duggal, M.I. Love, R.A. Irizarry, and C. Kingsford. 2017. Salmon provides fast and bias-aware quantification of transcript expression. Nature Methods. 14:417-419.

Piali, L., A. Fichtd, H.J. Terpe, B.A. Imhof, and R.H. Gisler. 1995. Endothelial vascular cell adhesion molecule 1 expression is suppressed by melanoma and carcinoma. Journal of Experimental Medicine. 181:811-816.

Picelli, S., O.R. Faridani, Å.K. Björklund, G. Winberg, S. Sagasser, and R. Sandberg. 2014. Fulllength RNA-seq from single cells using Smart-seq2. Nat. Protoc. 9:171-181.

Seigner, J., M. Junker-Samek, A. Plaza, G. D'Urso, M. Masullo, S. Piacente, Y.M. HolperSchichl, and R. de Martin. 2019. A Symphytum officinale Root Extract Exerts Antiinflammatory Properties by Affecting Two Distinct Steps of NF-KB Signaling. Front Pharmacol. 10:289-289.

Shrimali, R.K., Z. Yu, M.R. Theoret, D. Chinnasamy, N.P. Restifo, and S.A. Rosenberg. 2010. Antiangiogenic agents can increase lymphocyte infiltration into tumor and enhance the effectiveness of adoptive immunotherapy of cancer. Cancer Research. 70:6171-6180.

Singh, B., R. Kosuru, S. Lakshmikanthan, M.G. Sorci-Thomas, D.X. Zhang, R. Sparapani, J. Vasquez-Vivar, and M. Chrzanowska. 2021. Endothelial Rap1 (Ras-Association Proximate 1) Restricts Inflammatory Signaling to Protect From the Progression of Atherosclerosis. Arteriosclerosis, Thrombosis, and Vascular Biology. 41:638-650. 
725 Subramanian, A., P. Tamayo, V.K. Mootha, S. Mukherjee, B.L. Ebert, M.A. Gillette, A.

726 Paulovich, S.L. Pomeroy, T.R. Golub, E.S. Lander, and J.P. Mesirov. 2005. Gene set enrichment analysis: A knowledge-based approach for interpreting genome-wide expression profiles. Proceedings of the National Academy of Sciences of the United States of America. 102:15545-15550.

Wilhelmsen, K., K. Farrar, and J. Hellman. 2013. Quantitative in vitro assay to measure neutrophil adhesion to activated primary human microvascular endothelial cells under static conditions. Journal of visualized experiments : JoVE:e50677-e50677.

Xin, G., A. Khatun, P. Topchyan, R. Zander, P.J. Volberding, Y. Chen, J. Shen, C. Fu, A. Jiang, W.A. See, and W. Cui. 2020. Pathogen-boosted adoptive cell transfer therapy induces endogenous antitumor immunity through antigen spreading. Cancer Immunology Research. 8:7-18.

Yan, J., F. Li, D.A. Ingram, and L.A. Quilliam. 2008. Rap1a is a key regulator of fibroblast growth factor 2-induced angiogenesis and together with Rap1b controls human 


\section{Supplemental Table 1: Key Resources and Antibodies}

743

\begin{tabular}{|c|c|c|c|c|}
\hline $\begin{array}{l}\text { Reagent type } \\
\text { (species) or } \\
\text { resource }\end{array}$ & Designation & $\begin{array}{l}\text { Source or } \\
\text { reference }\end{array}$ & Identifiers & $\begin{array}{l}\text { Additional } \\
\text { information }\end{array}$ \\
\hline (Mus musculus) & $\begin{array}{l}\text { VE-Cadh-CreN- } \\
\text { Rap1a }{ }^{+/+} \text {Rap1b } b^{\text {t/f }}\end{array}$ & $\begin{array}{l}\text { In house } \\
\text { breeding }\end{array}$ & & $\begin{array}{l}\text { C57BI/6 genetic } \\
\text { background }\end{array}$ \\
\hline (Mus musculus) & $\begin{array}{l}\text { VE-Cadh-CreY- } \\
\text { Rap1 }^{+/+}{ }^{+/ 2} 1 b^{f / f}\end{array}$ & $\begin{array}{l}\text { In house } \\
\text { breeding }\end{array}$ & & $\begin{array}{l}\text { C57BI/6 genetic } \\
\text { background }\end{array}$ \\
\hline (Mus musculus) & $\operatorname{Rap} \mathrm{B}^{(+/-)}$ & $\begin{array}{l}\text { In house } \\
\text { breeding }\end{array}$ & & $\begin{array}{l}\mathrm{C} 57 \mathrm{BI} / 6 \text { genetic } \\
\text { background }\end{array}$ \\
\hline (Mus musculus) & $\operatorname{Rap} \mathrm{B}^{(++)}$ & $\begin{array}{l}\text { In house } \\
\text { breeding }\end{array}$ & & $\begin{array}{l}\text { C57BI/6 genetic } \\
\text { background }\end{array}$ \\
\hline Other & $\begin{array}{l}\text { HUVECs( Human } \\
\text { Umbilical Vein } \\
\text { ECs) }\end{array}$ & ATCC & $\begin{array}{l}\text { Cat\# CRL-1730 } \\
\text { RRID:CVCL_2959 }\end{array}$ & \\
\hline Other & B16F10 & ATCC & $\begin{array}{l}\text { Cat\# CRL-6475 } \\
\text { RRID:CVCL_0159 }\end{array}$ & $\begin{array}{l}\text { Mouse melanoma cell } \\
\text { line }\end{array}$ \\
\hline Other & Jurkat E6-1 & ATCC & Cat\# TIB-152 & $\begin{array}{l}\text { Human T cell } \\
\text { leukemia cell line }\end{array}$ \\
\hline Other & Rap1B siRNA & Dharmacon & & 50nM in reaction \\
\hline Other & Control siRNA & Dharmacon & & 50nM in reaction \\
\hline $\begin{array}{l}\text { Chemical } \\
\text { compound, drug }\end{array}$ & TNF- $\alpha$ & Sigma-Aldrich & Cat\# H8916-10UG & 50nM in assay \\
\hline $\begin{array}{l}\text { Chemical } \\
\text { compound, drug }\end{array}$ & VEGF & Sigma-Aldrich & Cat\# V7259 & $50 \mathrm{ng} / \mathrm{ml}$ in assay \\
\hline $\begin{array}{l}\text { Chemical } \\
\text { compound, drug }\end{array}$ & Calcein Blue AM & $\begin{array}{l}\text { BD } \\
\text { Biosciences }\end{array}$ & Cat\# 564060 & 5uM in assay \\
\hline Other & $\begin{array}{l}\text { pNL3.2.NF-kB- } \\
\text { RE[NlucP/NF-kB- } \\
\text { RE/Hygro] Vector }\end{array}$ & Promega & Cat\#N1111 & 2 ug in assay \\
\hline Other & pNL3.2.CMV & Promega & Cat\#N1411 & 2 ug in assay \\
\hline Assay kit & $\begin{array}{l}\text { Nano-Glo® } \\
\text { Luciferase Assay } \\
\text { System }\end{array}$ & Promega & Cat.\# N1110 & \\
\hline Antibody & $\begin{array}{l}\text { VCAM-1 (clone } \\
\text { E1E8X) Rabbit } \\
\text { mAb antibody }\end{array}$ & $\begin{array}{l}\text { Cell Signaling } \\
\text { Technology }\end{array}$ & $\begin{array}{l}\text { Cat\# 13662, } \\
\text { RRID:AB_2798286 }\end{array}$ & WB (1:2000) \\
\hline Antibody & $\begin{array}{l}\text { Rap1A/Rap1B } \\
\text { (clone 26B4) } \\
\text { Rabbit mAb } \\
\text { antibody }\end{array}$ & $\begin{array}{l}\text { Cell Signaling } \\
\text { Technology }\end{array}$ & $\begin{array}{l}\text { Cat\# 2399, } \\
\text { RRID:AB_2284915 }\end{array}$ & WB $(1: 2000)$ \\
\hline Antibody & $\begin{array}{l}\beta \text {-Actin mouse, } \\
\text { rat, human (clone } \\
\text { C4) mAb antibody }\end{array}$ & $\begin{array}{l}\text { Santa Cruz } \\
\text { Biotechnology }\end{array}$ & $\begin{array}{l}\text { Cat\# sc-47778 } \\
\text { RRID:AB_2714189 }\end{array}$ & WB (1:500) \\
\hline $\begin{array}{l}\text { Software, } \\
\text { algorithm }\end{array}$ & $\begin{array}{l}\text { GraphPad Prism } \\
\text { version } 5.02\end{array}$ & $\begin{array}{l}\text { GraphPad } \\
\text { Software }\end{array}$ & & \\
\hline $\begin{array}{l}\text { Software, } \\
\text { algorithm }\end{array}$ & Flow Jo software & & & \\
\hline Antibody & $\begin{array}{l}\text { FITC anti-mouse } \\
\text { CD3, clone: } \\
\text { 145-2C11 }\end{array}$ & Bio Legend & $\begin{array}{l}\text { Cat\# 100305, } \\
\text { RRID:AB_312670 }\end{array}$ & $\begin{array}{l}\text { Dilution: } 1: 300 \\
\text { For Tumor Infiltrate } \\
\text { Lymphocyte (TIL) }\end{array}$ \\
\hline
\end{tabular}




\begin{tabular}{|c|c|c|c|c|}
\hline & $\begin{array}{l}\text { Armenian } \\
\text { Hamster- } \\
\text { monoclonal) }\end{array}$ & & & $\begin{array}{l}\text { analysis by flow } \\
\text { cytometry }\end{array}$ \\
\hline Antibody & $\begin{array}{l}\text { APC anti-mouse } \\
\text { CD4, Clone } \\
\text { GK1.5, (rat- } \\
\text { monoclonal) }\end{array}$ & Bio Legend & $\begin{array}{l}\text { Cat\# 100412, } \\
\text { RRID:AB_312697 }\end{array}$ & $\begin{array}{l}\text { Dilution: } 1: 400 \\
\text { For TIL analysis by } \\
\text { flow cytometry }\end{array}$ \\
\hline Antibody & $\begin{array}{l}\text { FITC anti-mouse } \\
\text { CD4, Clone } \\
\text { GK1.5, (rat- } \\
\text { monoclonal) }\end{array}$ & Bio Legend & $\begin{array}{l}\text { Cat\# 100405, } \\
\text { RRID:AB_312690 }\end{array}$ & $\begin{array}{l}\text { Dilution: 1:400 } \\
\text { For TIL analysis by } \\
\text { flow cytometry }\end{array}$ \\
\hline Antibody & $\begin{array}{l}\text { Brilliant Violet } \\
510(\mathrm{TM}) \text { anti- } \\
\text { mouse, Clone } \\
\text { M1/70, (rat- } \\
\text { monoclonal) }\end{array}$ & Bio Legend & $\begin{array}{l}\text { Cat\# 101263, } \\
\text { RRID:AB_2629529 }\end{array}$ & $\begin{array}{l}\text { Dilution: } 1: 400 \\
\text { For TIL analysis by } \\
\text { flow cytometry }\end{array}$ \\
\hline Antibody & $\begin{array}{l}\text { PE/Cyanine7 anti- } \\
\text { mouse CD31, } \\
\text { Clone 390, (rat- } \\
\text { monoclonal) }\end{array}$ & Bio Legend & $\begin{array}{l}\text { Cat\# 102418, } \\
\text { RRID:AB_830757 }\end{array}$ & $\begin{array}{l}\text { Dilution: } 1: 300 \\
\text { For TIL analysis by } \\
\text { flow cytometry }\end{array}$ \\
\hline Antibody & $\begin{array}{l}\text { APC/Cyanine7 } \\
\text { anti-mouse CD44, } \\
\text { Clone IM7, (rat- } \\
\text { monoclonal) }\end{array}$ & Bio Legend & $\begin{array}{l}\text { Cat\# 103028, } \\
\text { RRID:AB_830785 }\end{array}$ & $\begin{array}{l}\text { Dilution: } 1: 400 \\
\text { For TIL analysis by } \\
\text { flow cytometry }\end{array}$ \\
\hline Antibody & $\begin{array}{l}\text { PE/Cyanine5 anti- } \\
\text { mouse CD45, } \\
\text { Clone 30-F11, } \\
\text { (rat-monoclonal) }\end{array}$ & Bio Legend & $\begin{array}{l}\text { Cat\# 103109, } \\
\text { RRID:AB_312974 }\end{array}$ & $\begin{array}{l}\text { Dilution: } 1: 400 \\
\text { For TIL analysis by } \\
\text { flow cytometry }\end{array}$ \\
\hline Antibody & $\begin{array}{l}\text { APC/Cyanine7 } \\
\text { anti-mouse CD45, } \\
\text { Clone 30-F11, } \\
\text { (rat-monoclonal) }\end{array}$ & Bio Legend & $\begin{array}{l}\text { Cat\# 103116, } \\
\text { RRID:AB_312981 }\end{array}$ & $\begin{array}{l}\text { Dilution: } 1: 400 \\
\text { For TIL analysis by } \\
\text { flow cytometry }\end{array}$ \\
\hline Antibody & $\begin{array}{l}\text { PE/Dazzle(TM) } \\
594 \text { anti-mouse, } \\
\text { clone RA3-6B2, } \\
\text { (rat-monoclonal) }\end{array}$ & Bio Legend & $\begin{array}{l}\text { Cat\# 103258, } \\
\text { RRID:AB_2564053 }\end{array}$ & $\begin{array}{l}\text { Dilution: } 1: 200 \\
\text { For TIL analysis by } \\
\text { flow cytometry }\end{array}$ \\
\hline Antibody & $\begin{array}{l}\text { Pacific Blue(TM) } \\
\text { anti-mouse F4/80, } \\
\text { Clone BM8, (rat- } \\
\text { monoclonal) }\end{array}$ & Bio Legend & $\begin{array}{l}\text { Cat\# 123124, } \\
\text { RRID:AB_893475 }\end{array}$ & $\begin{array}{l}\text { Dilution: } 1: 300 \\
\text { For TIL analysis by } \\
\text { flow cytometry }\end{array}$ \\
\hline Antibody & $\begin{array}{l}\text { Alexa Fluor(R) } \\
700 \text { anti-mouse } \\
\text { Ly-6G, Clone } 1 \mathrm{~A} 8, \\
\text { (rat-monoclonal) }\end{array}$ & Bio Legend & $\begin{array}{l}\text { Cat\# 127622, } \\
\text { RRID:AB_10643269 }\end{array}$ & $\begin{array}{l}\text { Dilution: } 1: 300 \\
\text { For TIL analysis by } \\
\text { flow cytometry }\end{array}$ \\
\hline Antibody & $\begin{array}{l}\text { PE anti-mouse Ly- } \\
6 \mathrm{C} \text {, Clone HK1.4, } \\
\text { (rat-monoclonal) }\end{array}$ & Bio Legend & $\begin{array}{l}\text { Cat\# 128007, } \\
\text { RRID:AB_1186133 }\end{array}$ & $\begin{array}{l}\text { Dilution: } 1: 300 \\
\text { For TIL analysis by } \\
\text { flow cytometry }\end{array}$ \\
\hline Antibody & $\begin{array}{l}\text { PerCP anti-mouse } \\
\text { Ly-6G/Ly-6C (Gr- } \\
\text { 1), Clone RB6- } \\
\text { 8C5, (rat- } \\
\text { monoclonal) }\end{array}$ & Bio Legend & $\begin{array}{l}\text { Cat\# 108425, } \\
\text { RRID:AB_893560 }\end{array}$ & $\begin{array}{l}\text { Dilution: } 1: 400 \\
\text { For TIL analysis by } \\
\text { flow cytometry }\end{array}$ \\
\hline Antibody & $\begin{array}{l}\text { APC anti-mouse } \\
\text { NK-1.1, Clone } \\
\text { PK136, (rat- }\end{array}$ & Bio Legend & $\begin{array}{l}\text { Cat\# 108709, } \\
\text { RRID:AB_313396 }\end{array}$ & $\begin{array}{l}\text { Dilution: } 1: 200 \\
\text { For TIL analysis by } \\
\text { flow cytometry }\end{array}$ \\
\hline
\end{tabular}


bioRxiv preprint doi: https://doi.org/10.1101/2021.11.03.467057; this version posted November 4, 2021. The copyright holder for this preprint (which was not certified by peer review) is the author/funder, who has granted bioRxiv a license to display the preprint in perpetuity. It is made available under aCC-BY 4.0 International license.

\begin{tabular}{|c|c|c|c|c|}
\hline & monoclonal) & & & \\
\hline Antibody & $\begin{array}{l}\text { PE anti-mouse } \\
\text { CD8a, Clone 53- } \\
6.7 \text {, (rat- } \\
\text { monoclonal) }\end{array}$ & $\begin{array}{l}\text { Thermo } \\
\text { Fisher } \\
\text { Scientific }\end{array}$ & $\begin{array}{l}\text { Cat\# 12-0081-82, } \\
\text { RRID:AB_465530 }\end{array}$ & $\begin{array}{l}\text { Dilution: } 1: 200 \\
\text { For TIL analysis by } \\
\text { flow cytometry }\end{array}$ \\
\hline Antibody & $\begin{array}{l}\text { eFluor } 450 \text { anti- } \\
\text { mouse CD106 } \\
\text { (VCAM-1), Clone } \\
429 \text {, (rat- } \\
\text { monoclonal) }\end{array}$ & $\begin{array}{l}\text { Thermo } \\
\text { Fisher } \\
\text { Scientific }\end{array}$ & $\begin{array}{l}\text { Cat\# 48-1061-82, } \\
\text { RRID:AB_1633378) }\end{array}$ & $\begin{array}{l}\text { Dilution: } 1: 300 \\
\text { For TIL analysis by } \\
\text { flow cytometry }\end{array}$ \\
\hline Antibody & $\begin{array}{l}\text { FITC anti-mouse } \\
\text { CD54 (ICAM-1), } \\
\text { Clone YN1/1.7.4, } \\
\text { (rat-monoclonal) }\end{array}$ & $\begin{array}{l}\text { Thermo } \\
\text { Fisher } \\
\text { Scientific }\end{array}$ & $\begin{array}{l}\text { Cat\# 11-0541-82, } \\
\text { RRID:AB_465094) }\end{array}$ & $\begin{array}{l}\text { Dilution: } 1: 300 \\
\text { For TIL analysis by } \\
\text { flow cytometry }\end{array}$ \\
\hline Antibody & $\begin{array}{l}\text { PE cy7 anti- } \\
\text { mouse Granzyme } \\
\mathrm{B}, \text { Clone NGZB, } \\
\text { (rat-monoclonal) }\end{array}$ & $\begin{array}{l}\text { Thermo } \\
\text { Fisher } \\
\text { Scientific }\end{array}$ & $\begin{array}{l}\text { Cat\# 25-8898-82, } \\
\text { RRID:AB_10853339 }\end{array}$ & $\begin{array}{l}\text { Dilution: } 1: 200 \\
\text { For TIL analysis by } \\
\text { flow cytometry }\end{array}$ \\
\hline Antibody & $\begin{array}{l}\text { eFluor 450-Rat } \\
\text { lgG1 k Isotype } \\
\text { control, Clone } \\
\text { eBRG1, (rat- } \\
\text { monoclonal) }\end{array}$ & $\begin{array}{l}\text { Thermo } \\
\text { Fisher } \\
\text { Scientific }\end{array}$ & $\begin{array}{l}\text { Cat\# 48-4301-82, } \\
\text { RRID:AB_1271984 }\end{array}$ & $\begin{array}{l}\text { Dilution: } 1: 200 \\
\text { For FMO control in } \\
\text { flow cytometry }\end{array}$ \\
\hline Antibody & $\begin{array}{l}\text { PE cy7-Rat lgG2a } \\
\text { K Isotype control, } \\
\text { Clone eBR2a, } \\
\text { (rat-monoclonal) }\end{array}$ & $\begin{array}{l}\text { Thermo } \\
\text { Fisher } \\
\text { Scientific }\end{array}$ & $\begin{array}{l}\text { Cat\# 25-4321-82, } \\
\text { RRID:AB_470200 }\end{array}$ & $\begin{array}{l}\text { Dilution: } 1: 200 \\
\text { For FMO control in } \\
\text { flow cytometry }\end{array}$ \\
\hline Antibody & $\begin{array}{l}\text { FITC-Rat IgG2b K } \\
\text { Isotype control, } \\
\text { Clone } \\
\text { eB149/10H5, (rat- } \\
\text { monoclonal) }\end{array}$ & $\begin{array}{l}\text { Thermo } \\
\text { Fisher } \\
\text { Scientific }\end{array}$ & $\begin{array}{l}\text { Cat\# 11-4031-82, } \\
\text { RRID:AB_470004) }\end{array}$ & $\begin{array}{l}\text { Dilution: } 1: 200 \\
\text { For FMO control in } \\
\text { flow cytometry }\end{array}$ \\
\hline
\end{tabular}


A.

B16F10: $1 * 10^{\wedge} 5$

cells (S.C.) Day-1

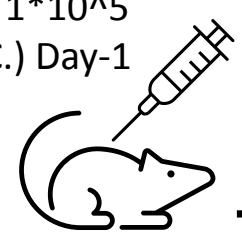

3

\section{monitoring}

B.

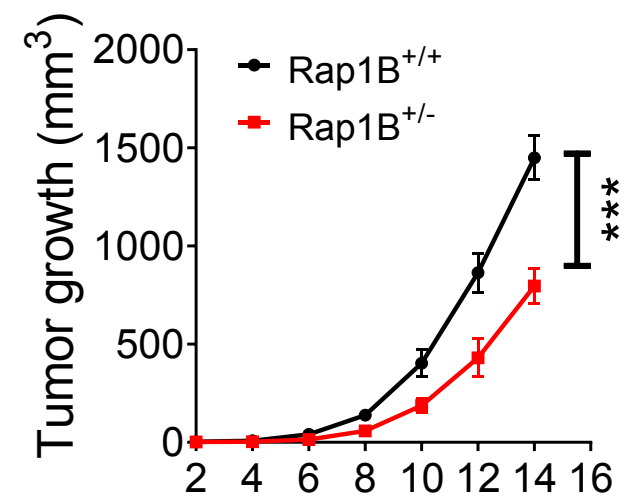

Days (post tumor-inoculation)

E.

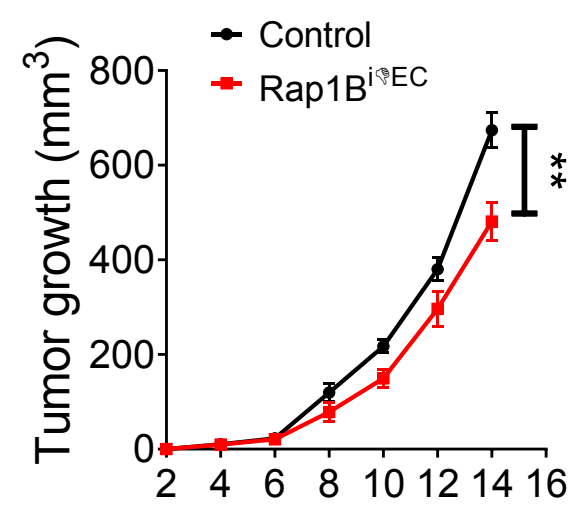

Days (post tumor-inoculation)
C.

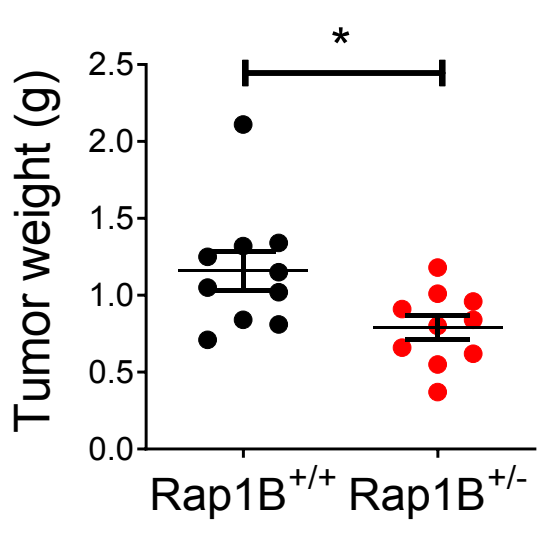

F.

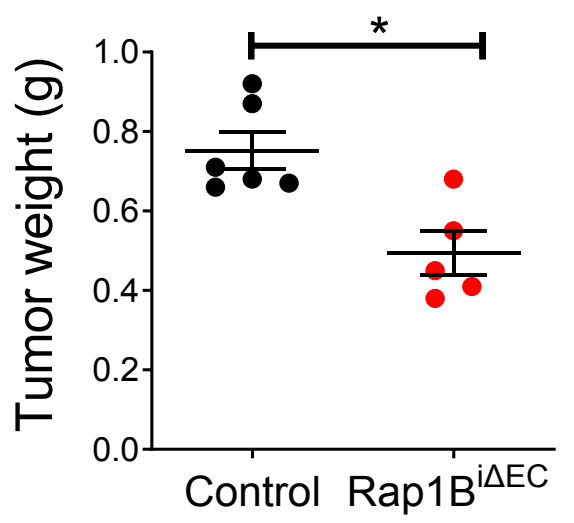

$\operatorname{Rap}^{\left(B^{(+/-)}\right.}$

vs. Rap1B ${ }^{(+/+)}$

(Tumor harvesting and

processing for flow cytometry)

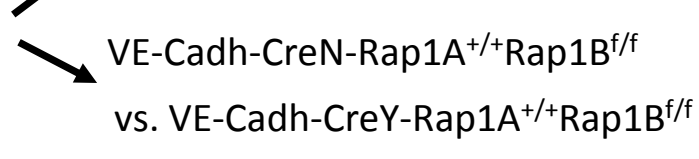

D.
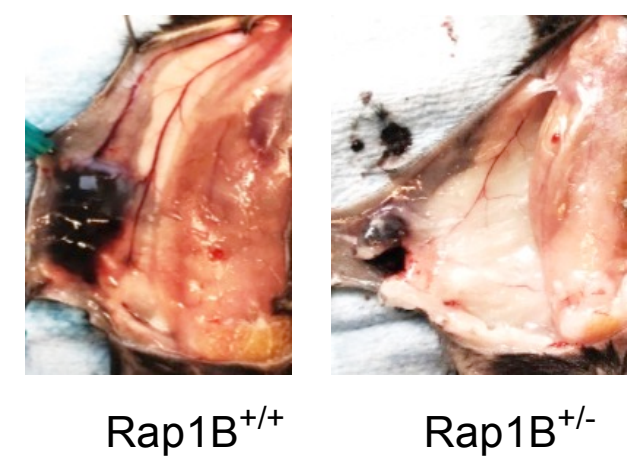

G.

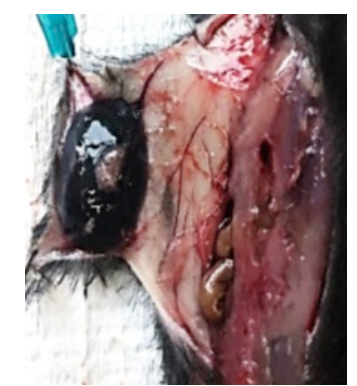

Control

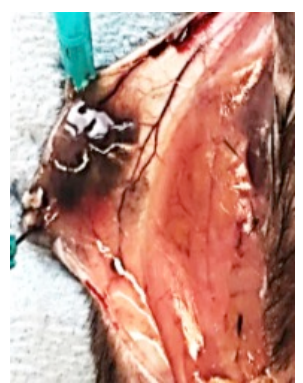

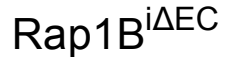

Figure 1. Global and EC-specific Rap1B deletion restricts tumor growth in vivo.

(A) A schematic diagram of melanoma induction in global Rap1B-deficient mice, Rap1B ${ }^{+/-}$, or EC-specific Rap1B knockouts, Rap1B ${ }^{\mathrm{i} \triangle \mathrm{EC}}$. Tumor growth kinetics (B), tumor weight at day 15 (C) and representative photographs of melanoma growth (D) in Rap1B ${ }^{+/-}(n=10)$ vs. Rap1B ${ }^{+/}(n=10)$ mice. Tumor growth kinetics (E), tumor weights (F) and representative photographs of melanoma growth (G) in Rap1B ${ }^{\mathrm{I} E \mathrm{EC}}(\mathrm{n}=5)$ vs. Cre-negative control mice $(n=6)$. Data represent mean \pm SEM. ${ }^{*}, \mathrm{P}<0.05^{* *}, \mathrm{P}<0.01, * * *, \mathrm{P}<0.001$, Student's $t$ test. Data and statistical outputs are available in Figure 1-source data 1 file. 
A.
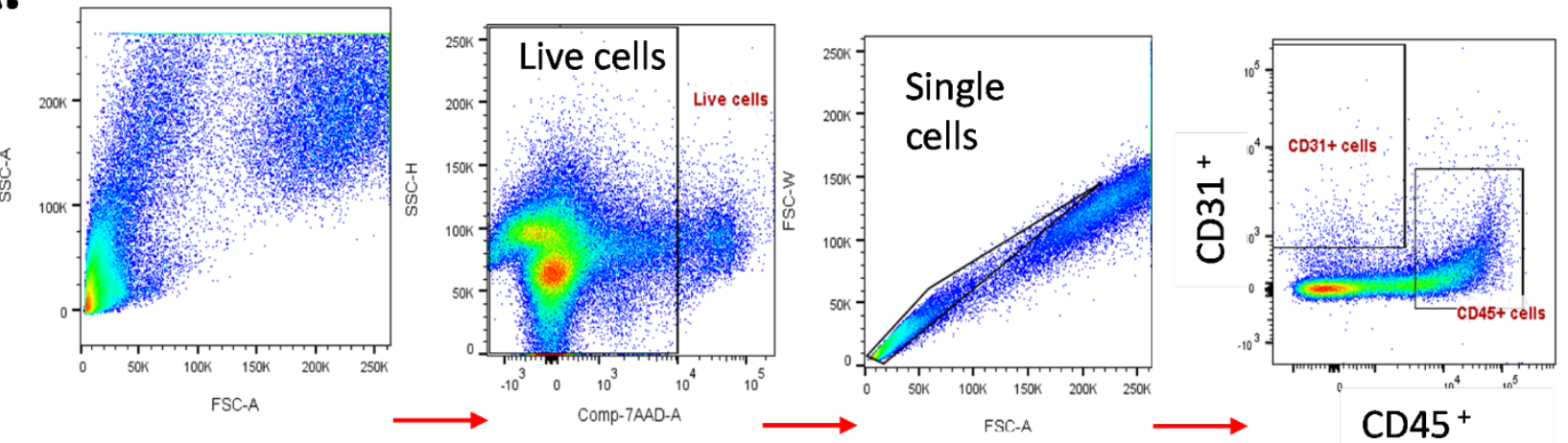

B.
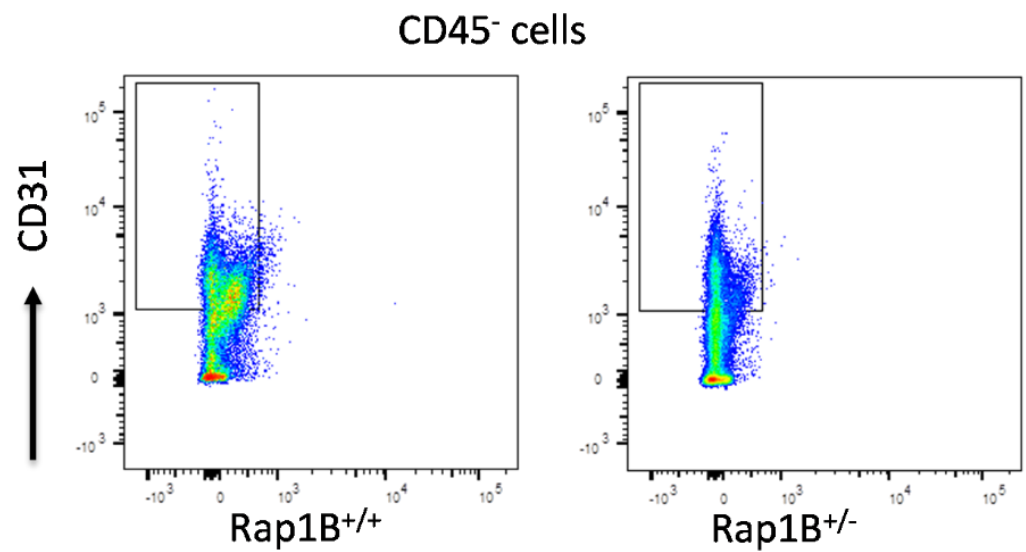

C.
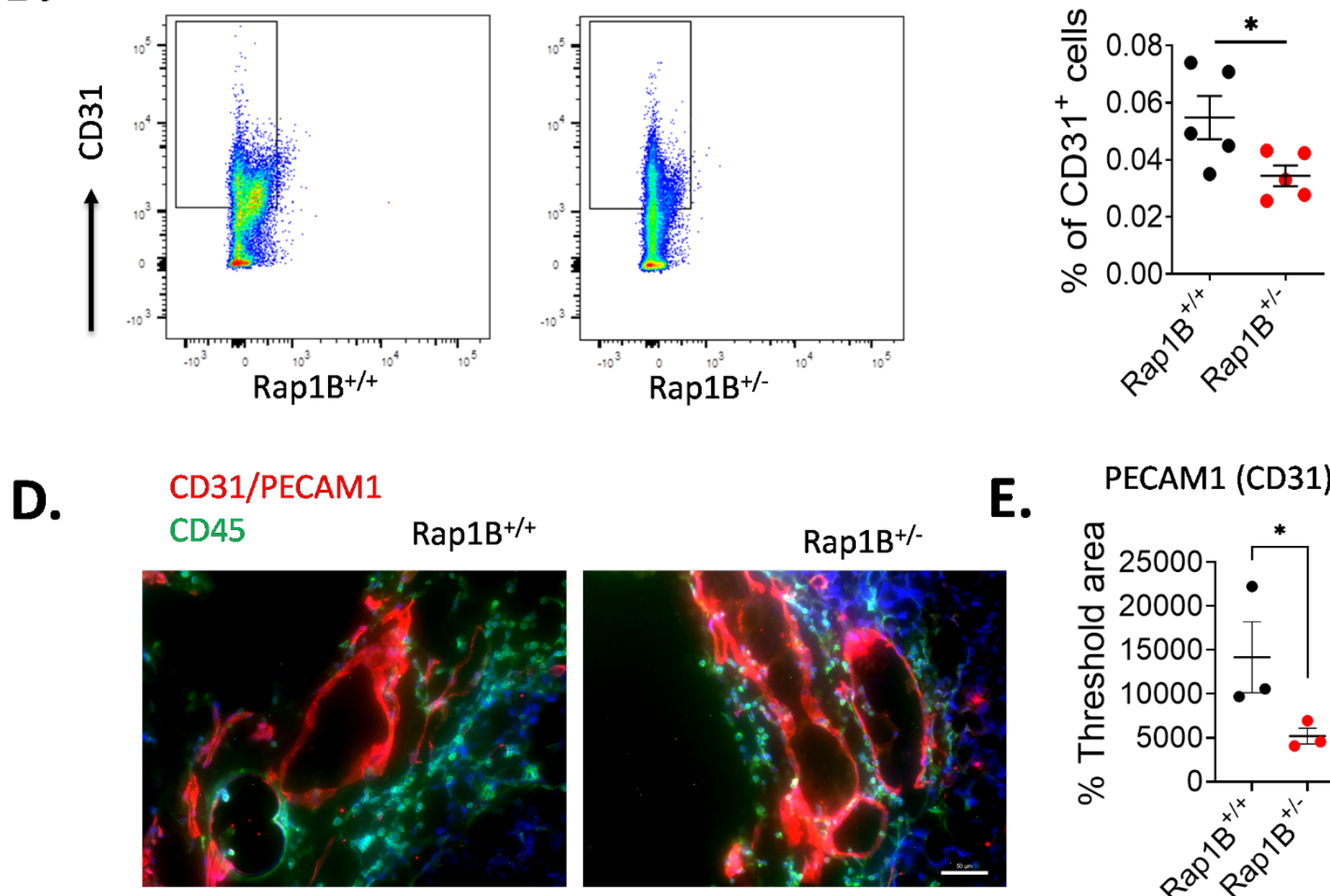

E. PECAM1 (CD31)

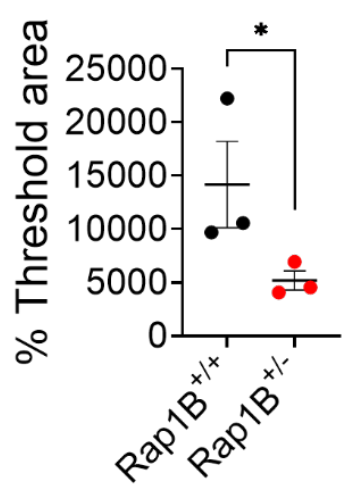

Figure 1- figure supplement 1. Reduced $\mathrm{CD} 1^{+}$endothelial cells in Rap1B ${ }^{+/-}$tumors. (A). Gating strategy for endothelial cells $\left(\mathrm{CD} 31^{+}\right)$and leukocytes $\left(\mathrm{CD} 45^{+}\right)$using stained single-cell suspension from the harvested tumors. Representative plots from a control tumor are shown. One million events were acquired on BD FACS-diva (LSR II-Green) using single-cell suspension from the harvested tumors. Viable, 7-AAD-negative cells were identified, and cell doublets were discriminated by their SSC and FSC characteristics. Single cells were further gated for leukocytes $\left(C D 45^{+} / C D 31^{-}\right)$and

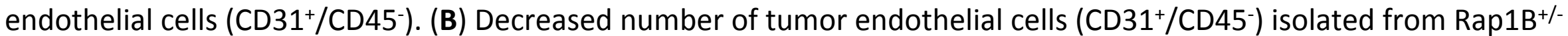
mice vs. control, shown as $\%$ of gated single cells $\left(C^{*}, P<0.05\right)$. Data are presented as the mean \pm S.E.M. $n=5$ mice per group, student's $t$ test. (D) Typical immunofluorescent staining of CD45+ cells (green) and CD31 endothelial cells (red) in tumor sections. (E) CD31+ endothelial cells quantification demonstrates a significant decrease in ECs in tumor sections in Rap1B ${ }^{+/}$, vs. control group ( $\left.*, P<0.05\right) . n=3$ mice per group, Student's $t$ test. Data and statistical outputs are available in Figure 1 -figure supplement 1-source data 1 file. 
A.

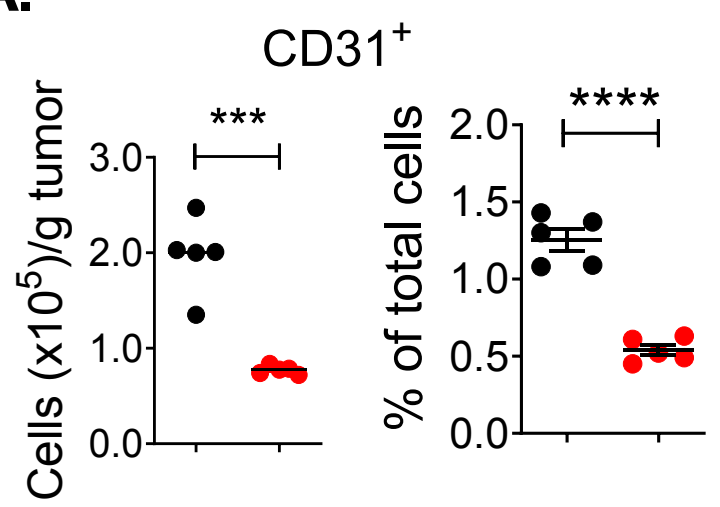

B.

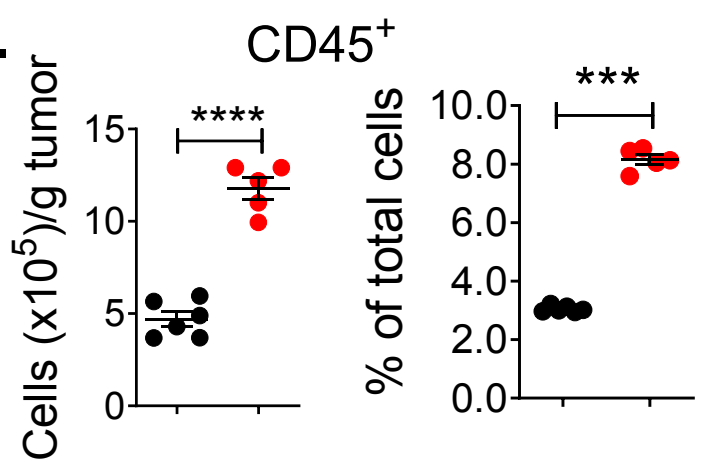

C.
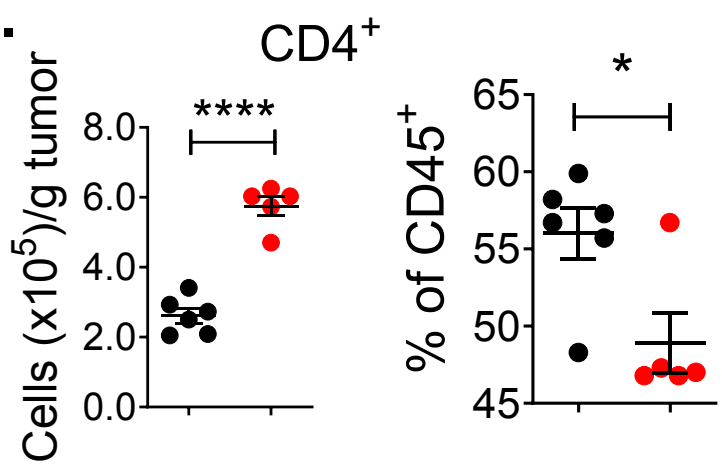

D.

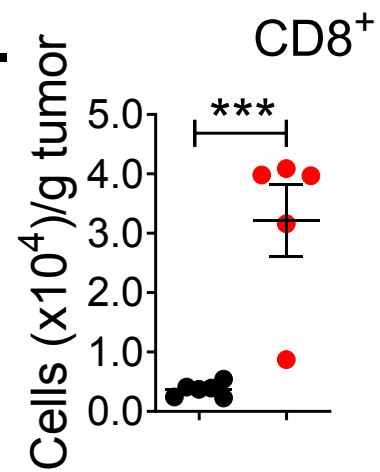

F.

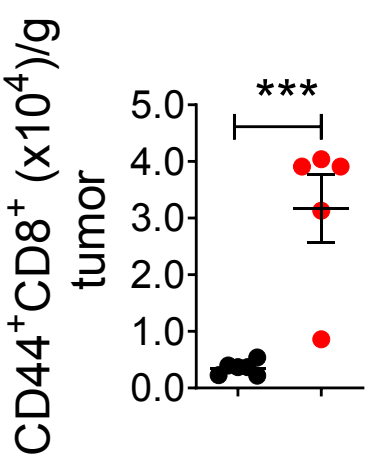

G.

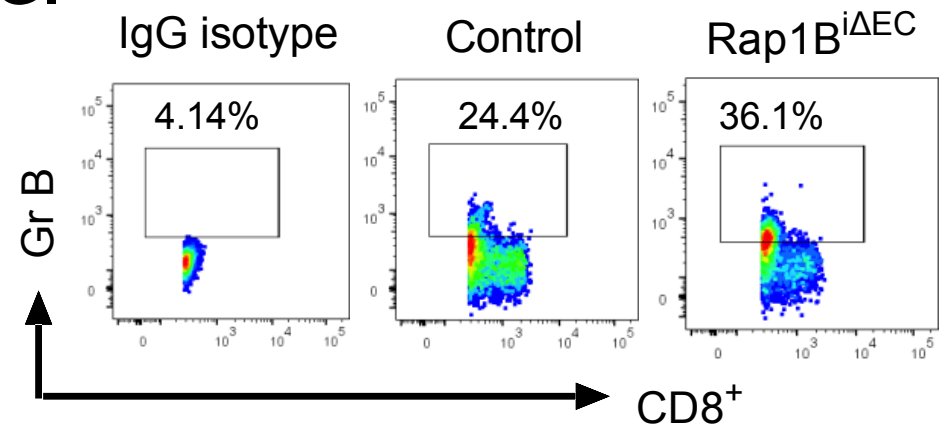

H.

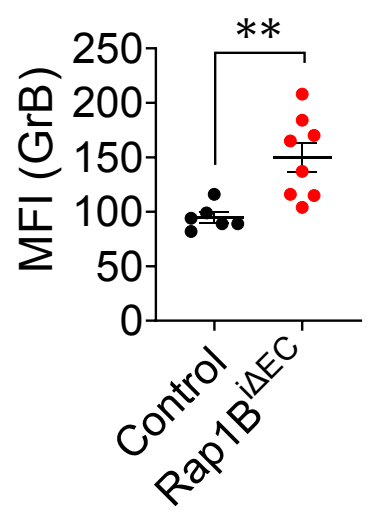

Figure 2. Endothelial Rap1B restricts tumor Tcell infiltration. (A-D)

Endothelial Rap1Bdeficiency alters TME cellularity. Flow

cytometry analysis of single cell suspensions from tumors stained with cell-type specific markers demonstrate decreased endothelial cell numbers $\left(\mathrm{CD} 31^{+}, \mathrm{A}\right)$, and increased CD45 ${ }^{+}$cells (B) in

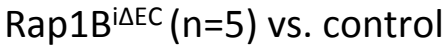
mice $(n=5)$. Gating strategy shown in Supplementary Fig. S1. $\mathrm{CD}^{+} \mathrm{T}$ cells $(\mathrm{C})$ and $\mathrm{CD} 8^{+} \mathrm{T}$ cells (D) selected as shown in gating scheme in Supplementary Fig. S3. (EH) Elevated $\mathrm{T}$ cell activation in Rap1B ${ }^{\mathrm{I} \Delta E C}$ vs. control mice. Surface expression of T-cell activation marker CD44 in $\mathrm{CD}^{+} \mathrm{T}(\mathrm{E})$ and $\mathrm{CD} 8^{+} \mathrm{T}(\mathrm{F})$ cells in $\operatorname{Rap} B^{\mathrm{i} \triangle \mathrm{EC}}(\mathrm{n}=5)$ and control mice $(n=6)$ tumors. (G-H)

Representative FACS plots (G) and quantification of median fluorescence intensity, (MFI, $\mathbf{H}$ ) of intracellular staining for granzyme $B(G r B)$ in tumor $\mathrm{CD} 8{ }^{+} \mathrm{T}$ cells from $\operatorname{Rap}_{1 B}{ }^{\mathrm{i} \triangle \mathrm{EC}}(\mathrm{n}=8)$ and control mice $(n=5)$. Data represent mean \pm SEM. *, $\mathrm{P}<0.05 * *, \mathrm{P}<0.01, * * *$, $\mathrm{P}<0.001$, Student's t-test. Data and statistical outputs are available in Figure 2-source data 1 file. 

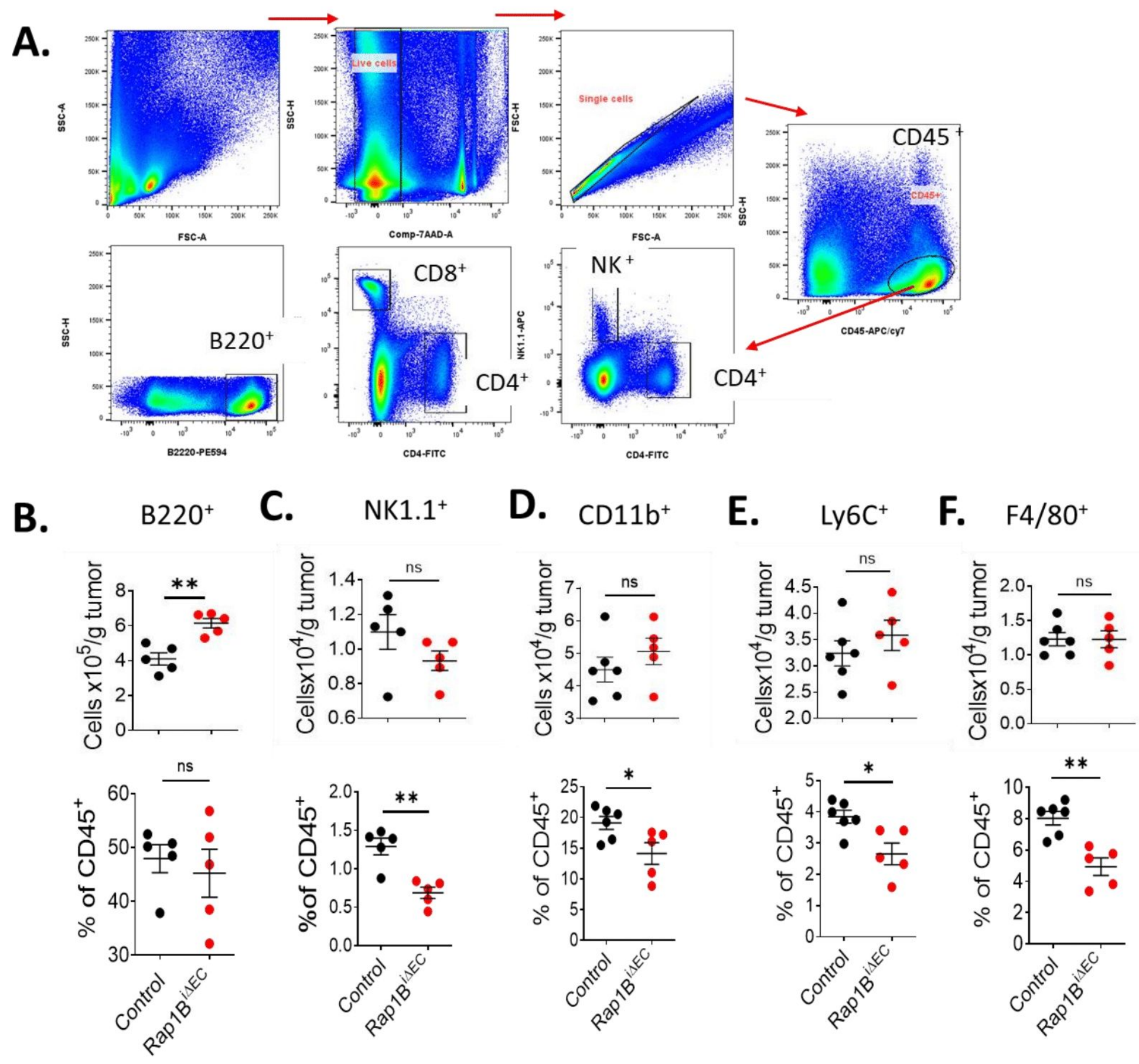

Figure 2-figure supplement 1. EC-specific Rap1B deletion alters recruitment of tumor-infiltrating lymphocytes (TIL). (A) Gating and selection of immune cell types from tumor single-cell suspensions. Representative plots from a control tumor are shown. One million events were acquired on BD FACS-diva (LSR II-Green) using single-cell suspension from the harvested tumors. Single cells were used to identify $C D 45^{+}$leukocytes, which were further gated using markerspecific antibodies against NK1.1 (natural killer cells), CD4, CD8 and B220 B-cells. B-F. Quantitation of cell

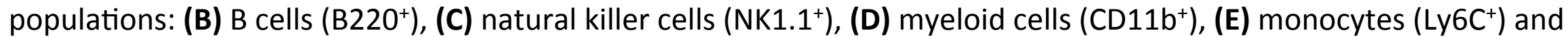
(F) macrophage $\left(\mathrm{F} 4 / 80^{+}\right)$in single-cell suspension of tumors from Rap1 $\mathrm{B}^{\mathrm{i} \triangle \mathrm{EC}}$ or control mice. Data are presented as the mean \pm S.E.M. *, $\mathrm{P}<0.05 . \mathrm{n}=5$ mice per group, Student's $t$ test. Data and statistical outputs are available in Figure 2-figure supplement 1-source data 1 file. 
A.

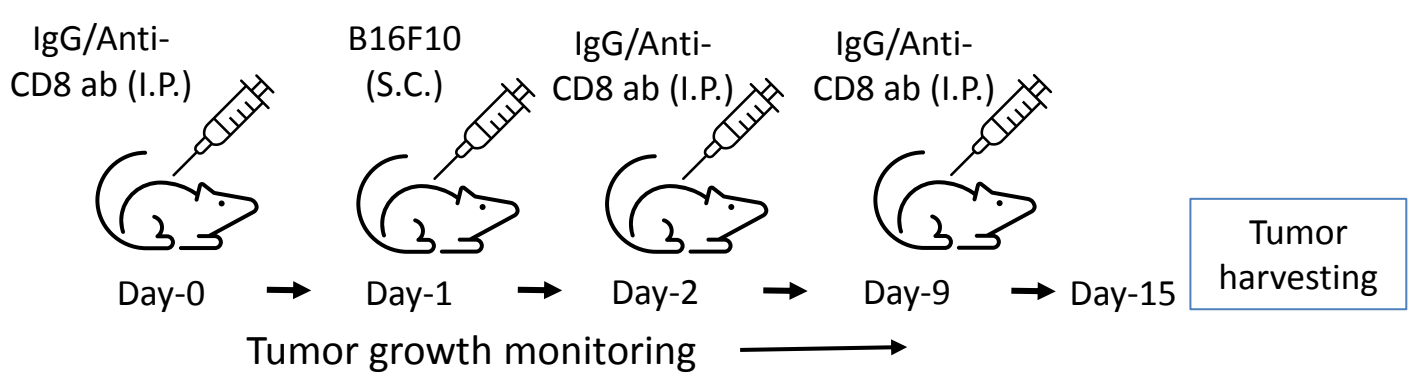

B.

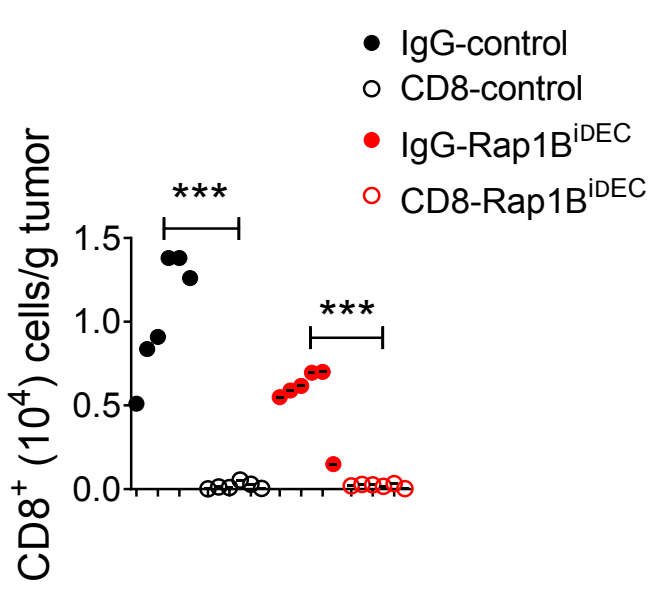

C.

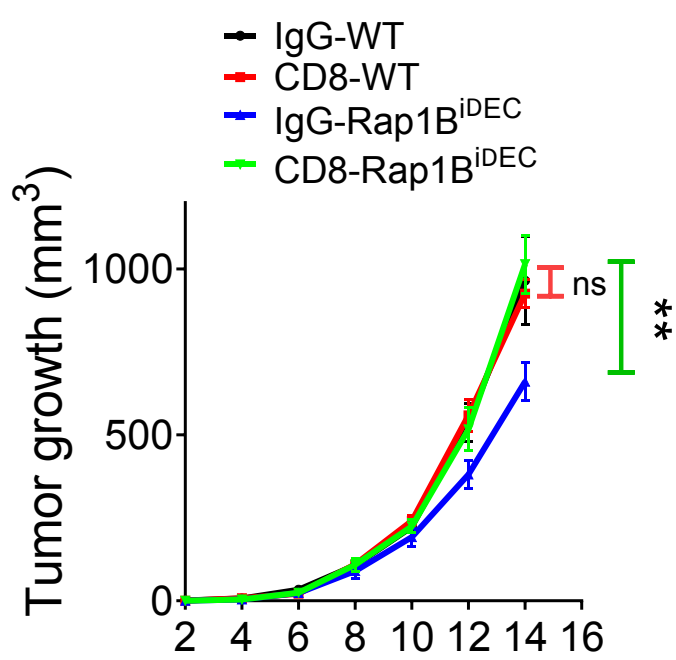

Days (post tumor-inoculation)
D.

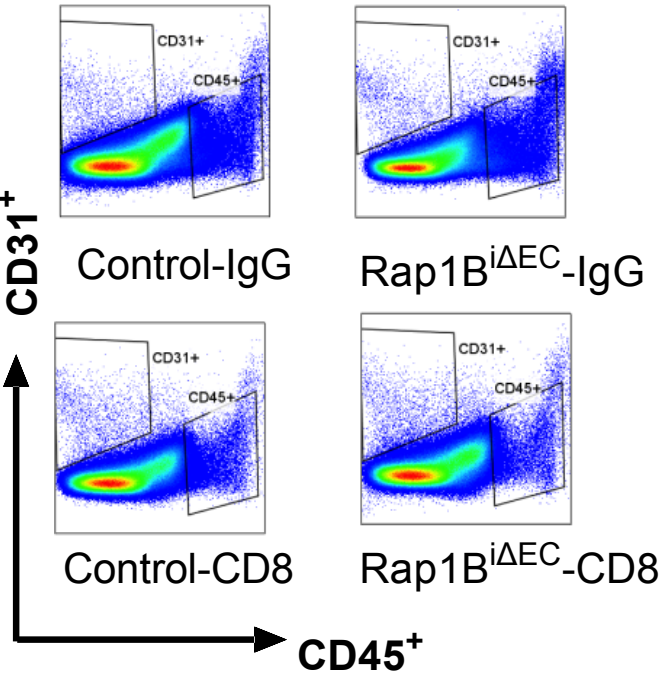

E.

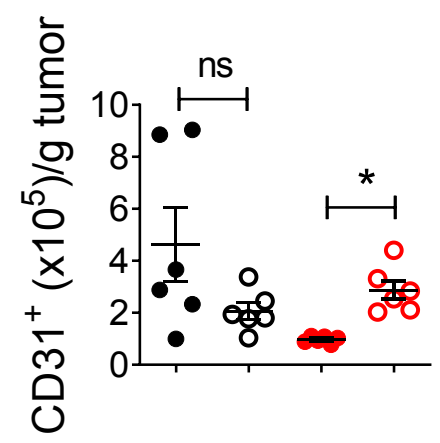

F.

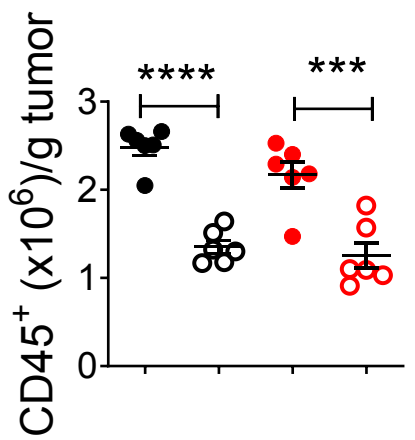

Figure 3. Depletion of CD8 ${ }^{+} \mathrm{T}$ cells normalizes tumor growth in Rap1B ${ }^{\mathrm{i} E E C}$ mice. (A) Schematic diagram of antibody treatment (intraperitoneal, I.P. injection) and melanoma induction (subcutaneous, S.C. injection). (B) Quantification of $\mathrm{CD} 8^{+} \mathrm{T}$ cells demonstrates highly efficient cell depletion in with antiCD8 antibody or IgG isotype control. (C) Tumor growth kinetics in Rap1B ${ }^{\mathrm{i} E \mathrm{EC}}$ vs. Crenegative control treated with anti-CD8 . (D) Gating scheme and quantification of $\mathrm{CD} 31^{+}$ ECs (E) and CD45+ cells (F). Data are presented as the mean \pm S.E.M $(n=6$ per group). ${ }^{*}, \mathrm{P}<0.05, * *, \mathrm{P}<$ $0.01, * * *, \mathrm{P}<0.001$, Panels $B, C$, F: one-way ANOVA with Tukey's post hoc test. Panel E: Student's t-test. Data and statistical outputs are available in Figure 3-source data 1 file. 
- IgG-control $\circ$ CD8-control $\bullet \operatorname{lgG}-R a p 1 B^{i \Lambda E C} \circ \mathrm{CD} 8-R a p 1 B^{i \Lambda E C}$
A.
B.
C.
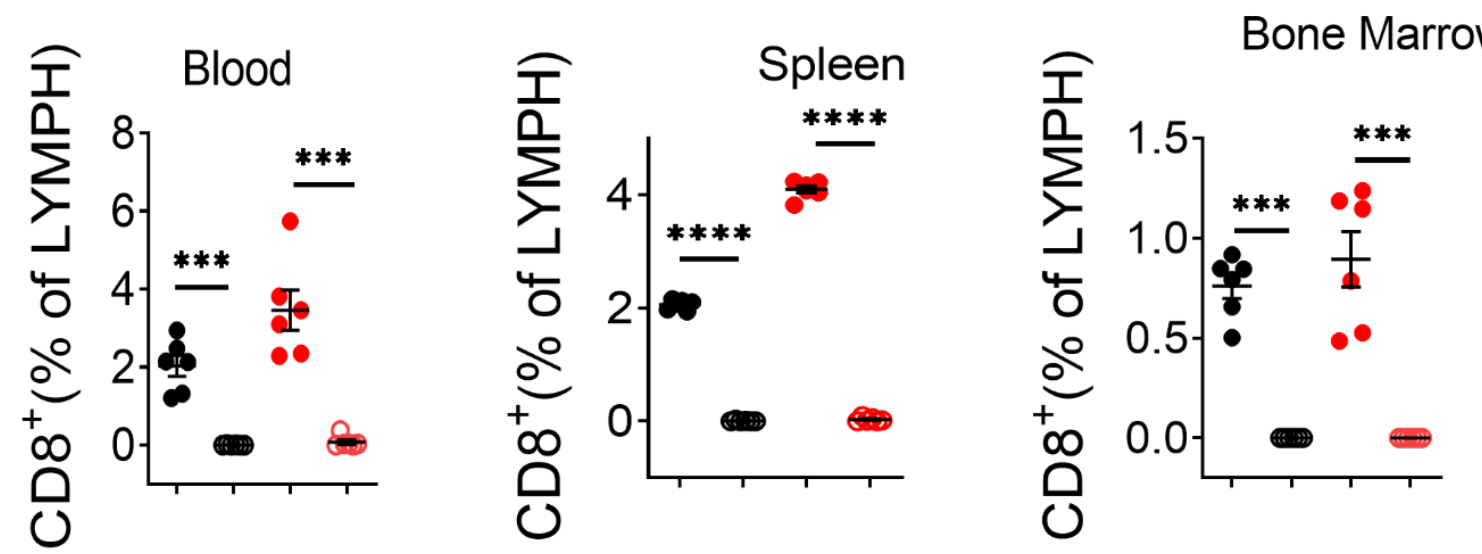

Figure 3 - figure supplement 1. Efficiency of $\mathrm{CD8}^{+} \mathrm{T}$ cell depletion in specific tissue compartments.

Peripheral blood cells (A), spleen cells (B) and bone marrow cells $(\mathbf{C})$ were stained with Very CD8 mAb. Flow analysis showing drastic depletion of $\mathrm{CD}^{+}$cells in all tissue compartment. IgG isotype control has no significant modulation on T cell. Data are presented as the mean \pm S.E.M. ${ }^{* * *}, \mathrm{P}<0.001, * * * *, \mathrm{P}<0.0001 . \mathrm{n}=6$ mice per group, one-way ANOVA with Tukey's multiple comparisons post hoc test. Data and statistical outputs are available in Figure 3 - figure supplement 1-source data 1 file. 


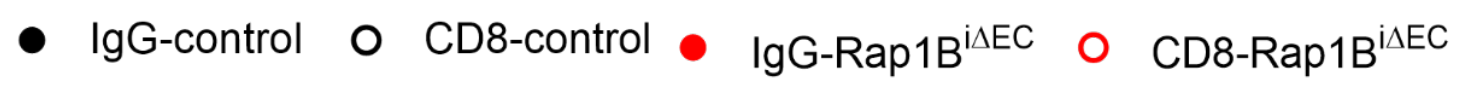

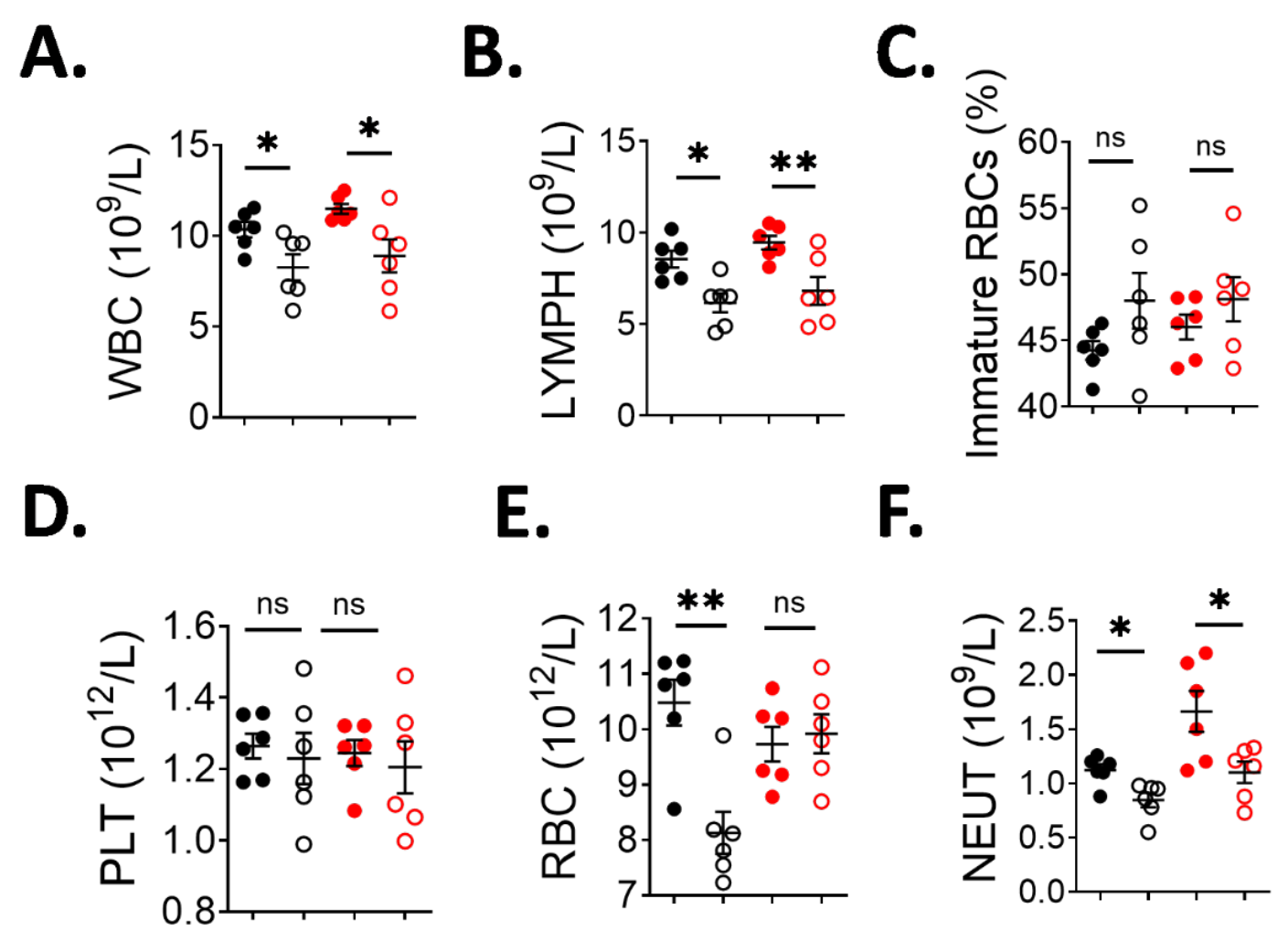

Figure 3 - figure supplement 2. Hematological (CBC) analysis in control and Rap1B ${ }^{\mathrm{i} E \mathrm{EC}}$ mice after CD8 ${ }^{+}$T cell depletion. Whole blood (13 $\mu$ l per mouse) was collected into anticoagulant (1:10) using capillary tubes (StatSpin ${ }^{\circledR}$ Microhematocrit Tubes, VWR). The blood samples were immediately analyzed using an automated Hematology blood analyzer (Sysmex XN-1000 ${ }^{\mathrm{TM}}$ ). CBC counts: (A) White blood cells (WBC) 10\% $/$; (B) lymphocyte (LYMPH) 10\%/L. (C) Immature (young) RBC fraction, as measured by \% of high fluorescence reticulocyte (HFR), (D) Platelets (PLT) $10^{12} / \mathrm{L}$, (E) Red blood cells (RBC) $10^{12} / \mathrm{L}$, and (F) Neutrophils (NEUT). Data are presented as the mean \pm S.E.M. * ${ }^{*} \mathrm{P}$ $<0.05, * *, \mathrm{P}<0.01 . \mathrm{n}=6$ mice per group, one-way ANOVA with Tukey's multiple comparisons post hoc test. Data and statistical outputs are available in Figure 3 - figure supplement 2-source data 1 file. 
A.
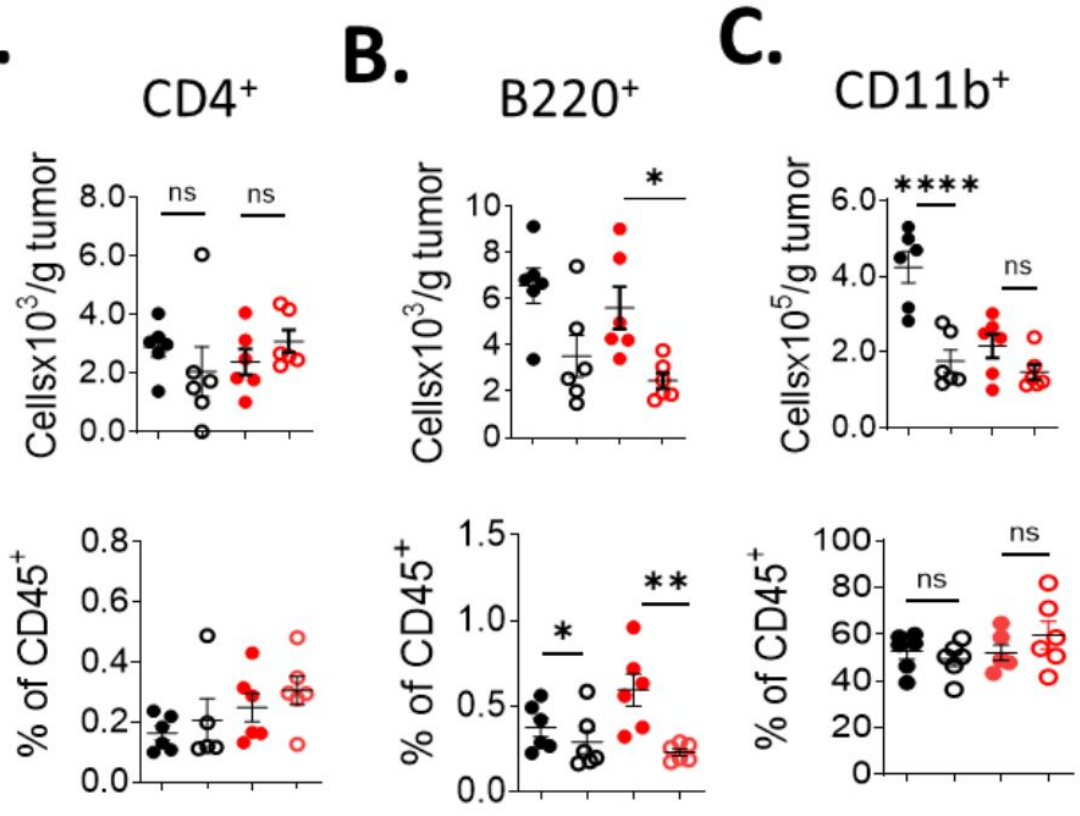

D.

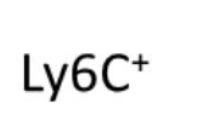

E.
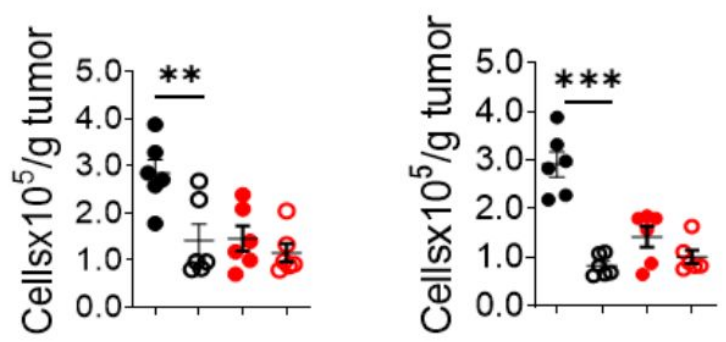

F. $\mathrm{F} 4 / 80^{+}$
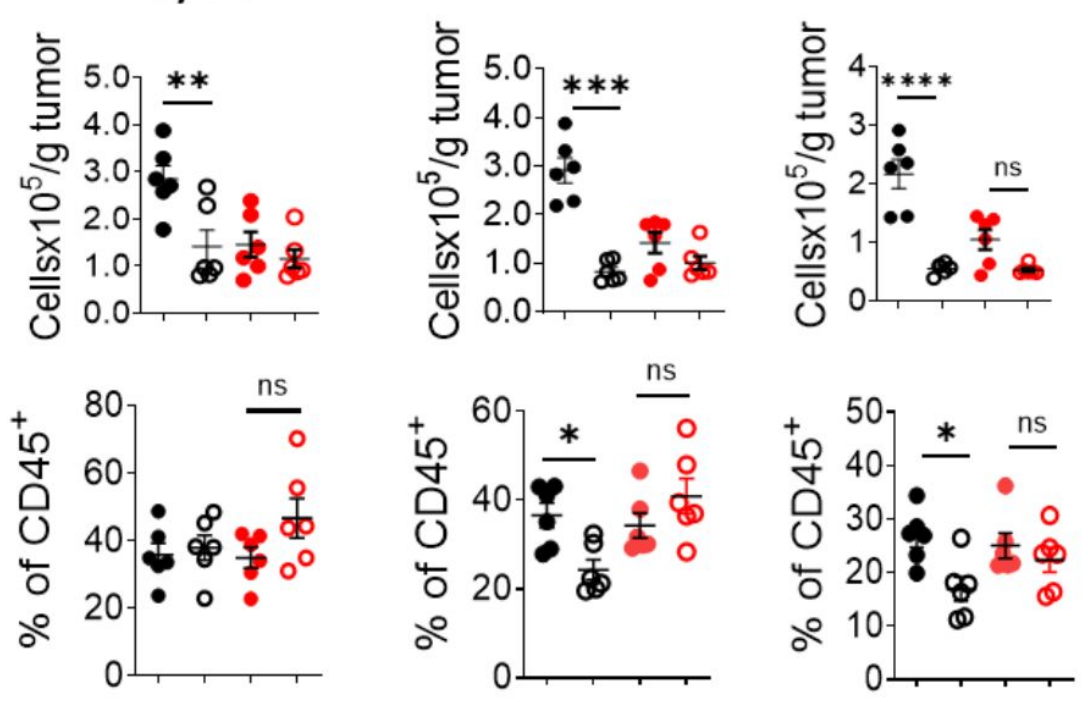

Figure 3 - figure supplement 3. Effect of CD8+ T-cell depletion on tumor-infiltrating lymphocytes (TIL) in control and Rap1B ${ }^{\mathrm{I} E \mathrm{EC}}$ mice. Immunophenotypic examination showing quantitation of (A) CD4 ${ }^{+} \mathrm{T}$ cells, (B) B cells (B220 ${ }^{+}$), (C) myeloid cells (CD11b+), (D) monocytes (Ly6C $C^{+}$), (E) neutrophils (Ly6G+) and (F) macrophage $\left(\mathrm{F} 4 / 80^{+}\right)$in $\mathrm{Rap}^{\mathrm{B}} \mathrm{B} \triangle \mathrm{EC} /$ control mice treated with either IgG isotope or CD8 $\mathrm{mAb}$. Data are presented as the mean $\pm \mathrm{S}$. E.M. * ${ }^{*} \mathrm{P}$ $<0.05, * *, \mathrm{P}<0.01 . \mathrm{n}=6$ mice per group, one-way ANOVA with Tukey's multiple comparisons post hoc test. Data and statistical outputs are available in Figure 3 -figure supplement 3-source data 1 file. 
A.

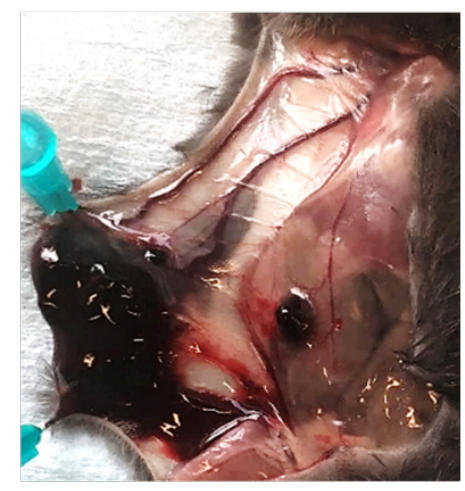

IgG-Control

B.

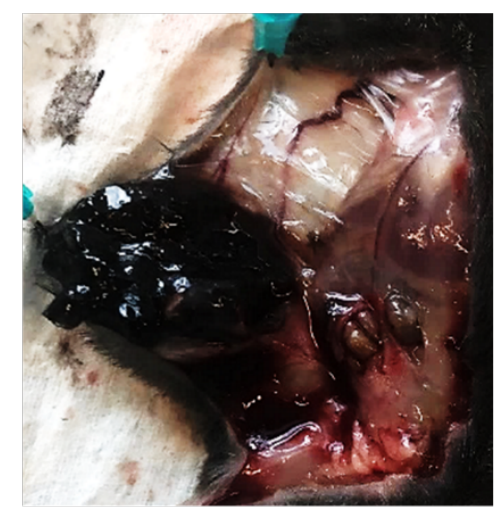

CD8-Control

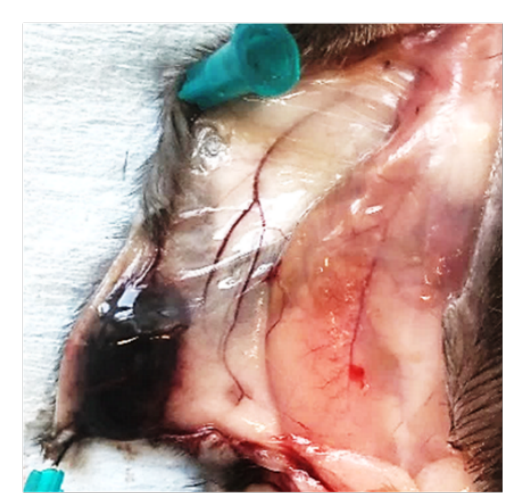

$\operatorname{lgG-Rap} 1 B^{\mathrm{i} \triangle \mathrm{EC}}$

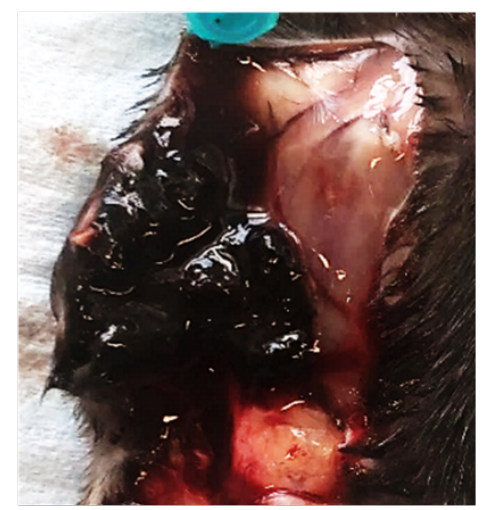

CD8-Rap1B ${ }^{\mathrm{i} \triangle \mathrm{EC}}$

Figure 3 - figure supplement 4. Depletion of CD8 ${ }^{+}$T-cells normalizes tumor growth in Rap1B ${ }^{\mathrm{i} \Delta \mathrm{EC}}$ mice.

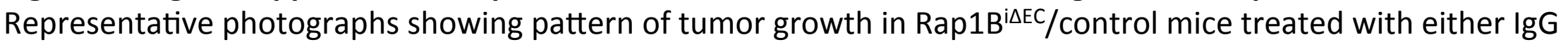
isotope or CD8 mAb. (A) IgG isotope has no effect on tumor growth in control group. (B) CD8 ${ }^{+} \mathrm{T}$ cell depletion significantly rescued tumor reduction in Rap1B ${ }^{\mathrm{i} \Delta \mathrm{EC}}$ mice group. 
A.

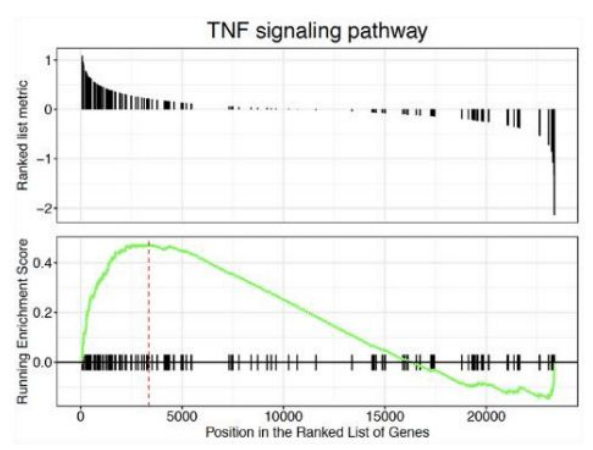

B.

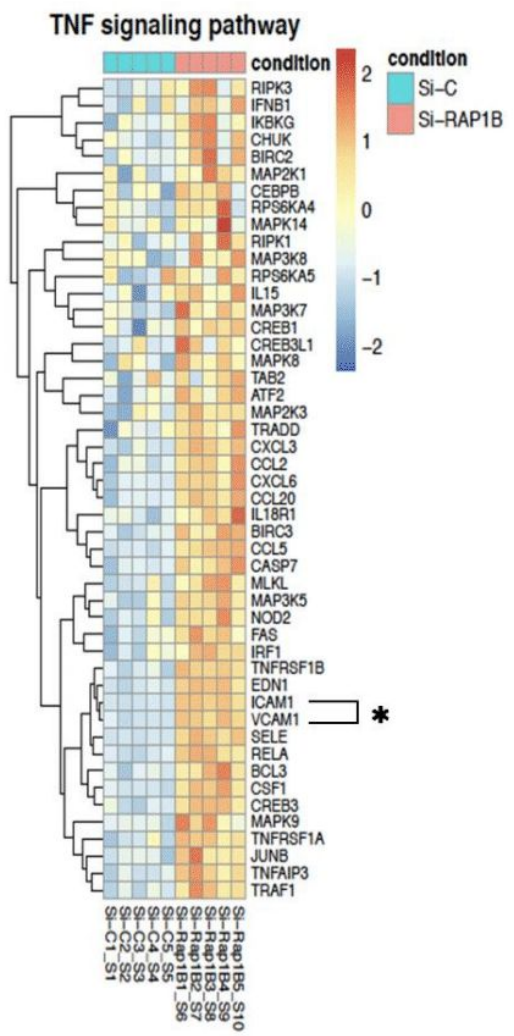

C.

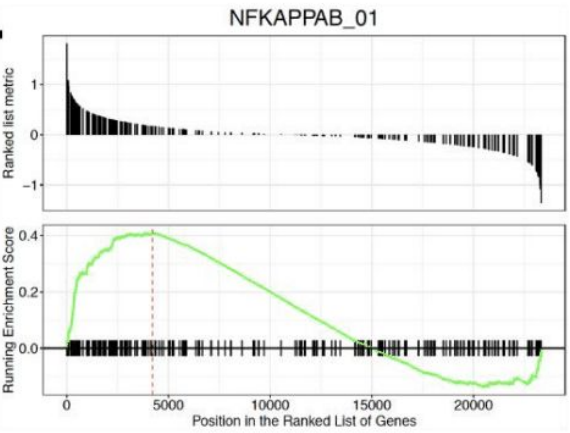

D.

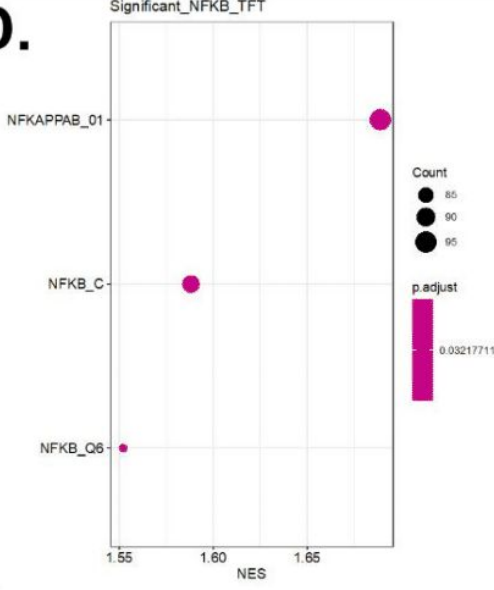

E. ${ }_{\text {siRap1B }}^{\text {sicontrol }}$

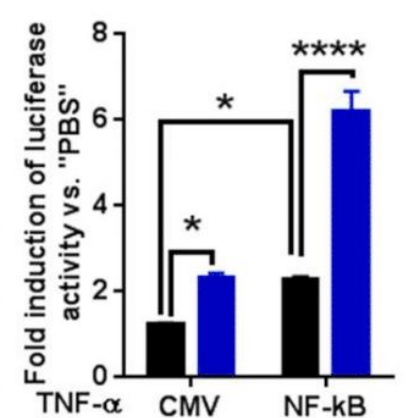

$\mathbf{F}$

F. NFKAPPAB_01

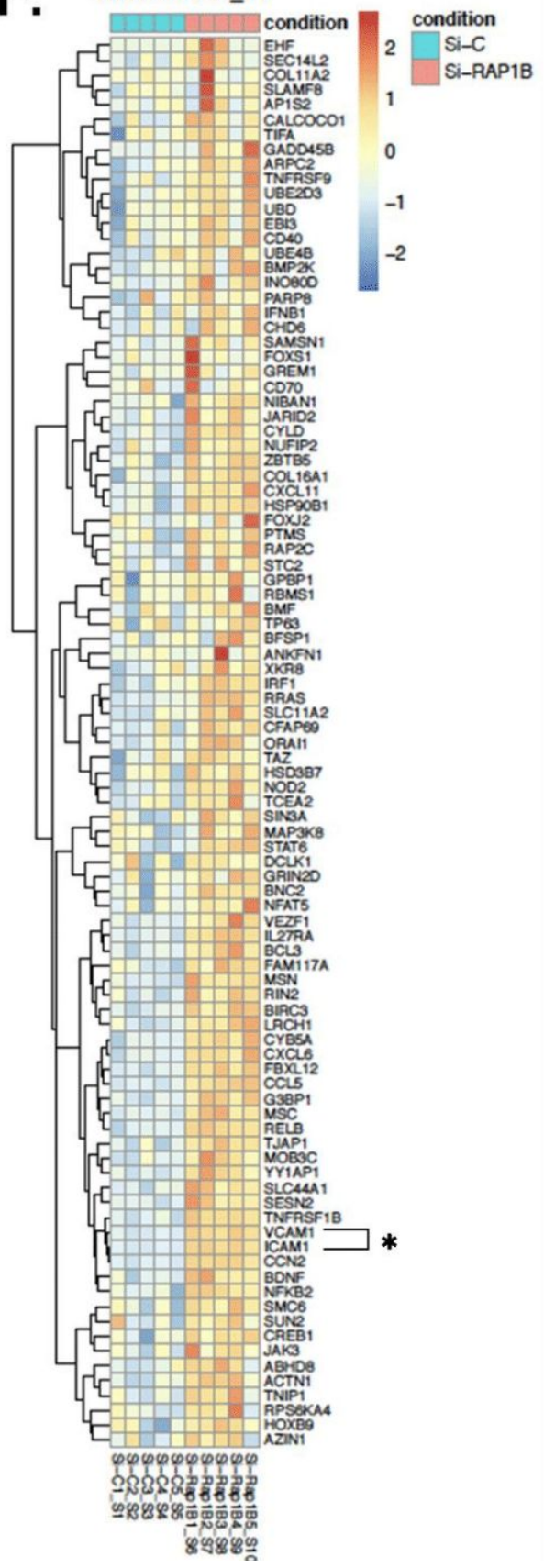

Figure 4. Endothelial Rap1B restricts TNF- $\alpha$ induced NFKB activation.

Increased TNF- $\alpha$ signaling and NFKB transcription detected by bulk RNA sequencing of TNF- $\alpha$-treated siRap1B and siControl Ecs. (A) Gene set enrichment analysis (GSEA) of genes in TNF- $\alpha$ signaling pathway upregulated in siRap1B vs. siControl. (B) Heatmap of selected genes from TNF- $\alpha$ signaling pathway. (C) GSEA of NFKB signaling pathway. (D) Transcriptional activation of NFKB in siRap1B ECs. (E) TNF- $\alpha$-induced NFKB activity determined by luciferase assay in cells transfected with NF-KB reporter construct or a control vector (CMV). Values shown as mean fold change vs. PBS-treated cells . Error bars represent mean $\pm S D(n=6) .{ }^{*}, P<0.05, * * *, P<0.0005$. One-way ANOVA followed by Tukey's multiple comparisons test. (F) Heatmap of selected genes from NFKB pathway. ( $n=5$ separate EC sets per group). Link to sequence data deposited within NCBI GEO is available in Figure 4-source data 1 file. Data and statistical outputs for panel E are available in Figure 4-source data 2 file. 
A.

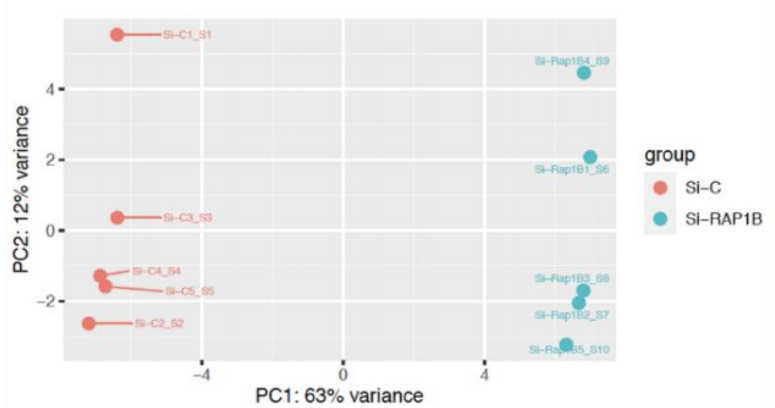

C. Additional GSEA of NFKB (different motifs) NFKB_C
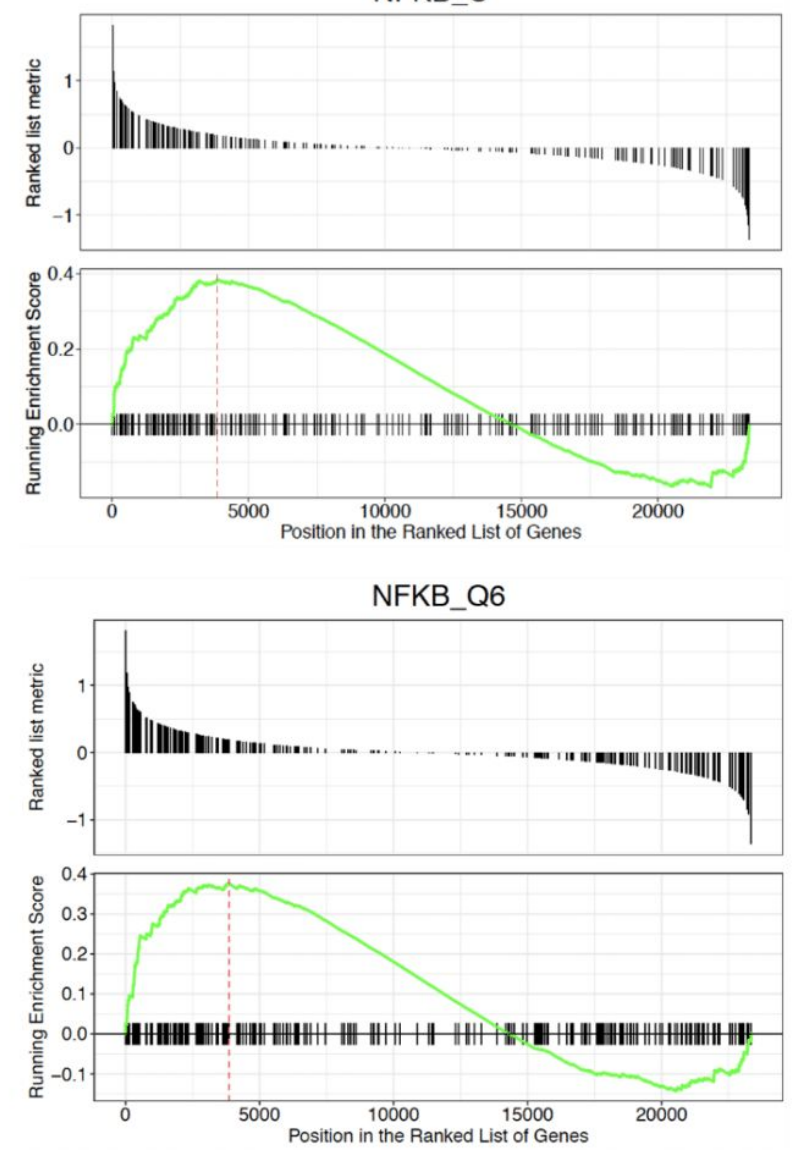

B.

Si-C vs Si-Rap1b

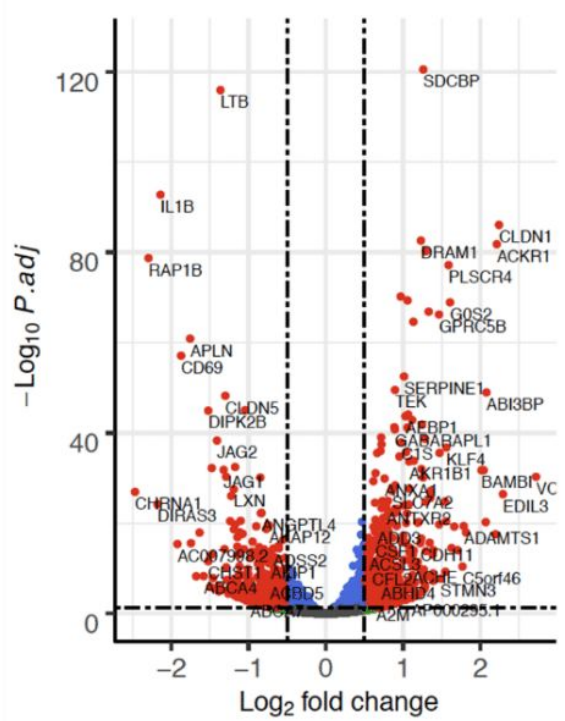

Total $=23354$ variables

D.

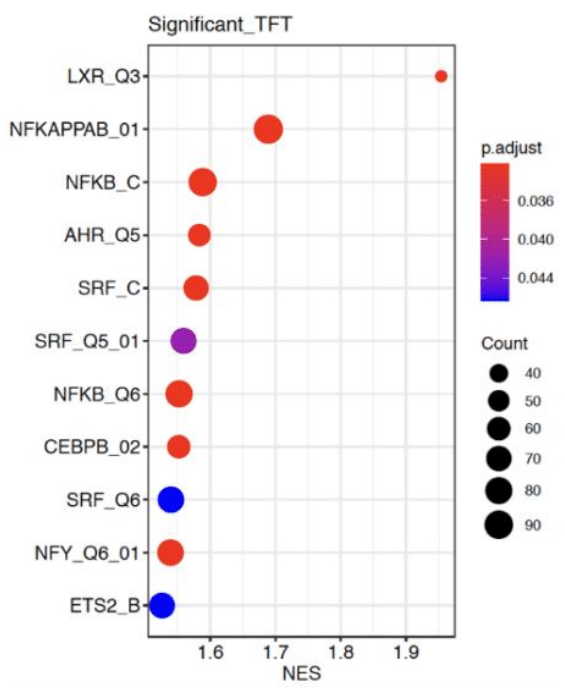

Figure 4 - figure supplement 1. Transcriptomic analysis of TNF- $\alpha$-stimulated siControl and siRap1B ECs. (A) Principal component analysis of samples. (B) Volcano plot of differential gene expression, the top 50 significantly differentially expressed genes are labeled. (C) Gene set enrichment analyses (GSEA) of NFkB target genes. (D) Dot plot of top significantly enriched transcription factors by GSEA $(n=5)$. Link to sequence data deposited within NCBI GEO is available in Figure 4-source data 1 file. 
A.

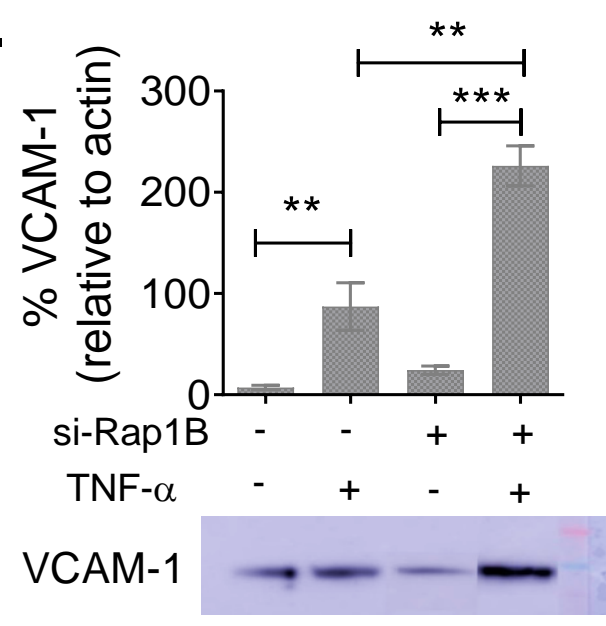

b-Actin

B.

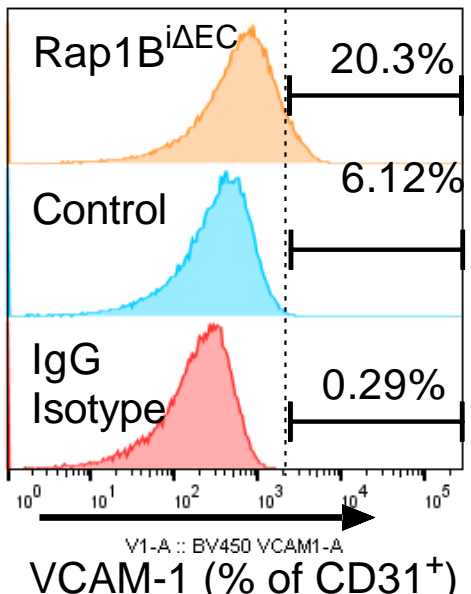

C.

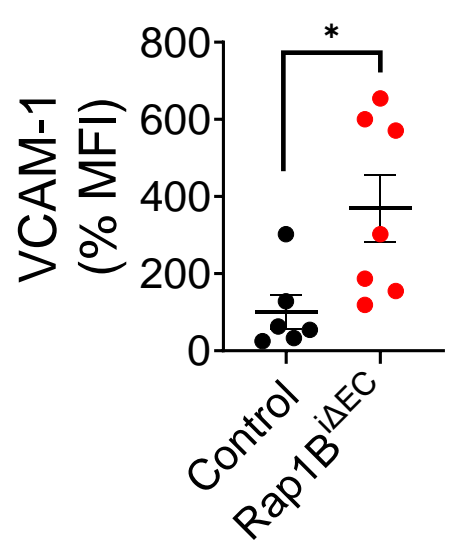

D.

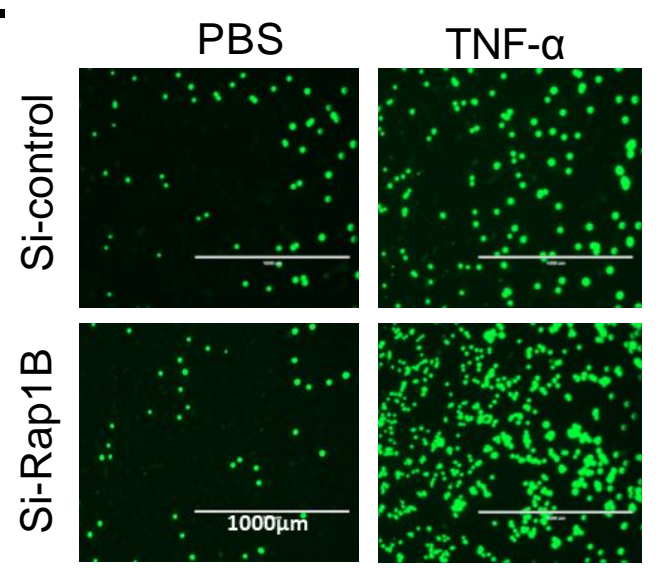

E.

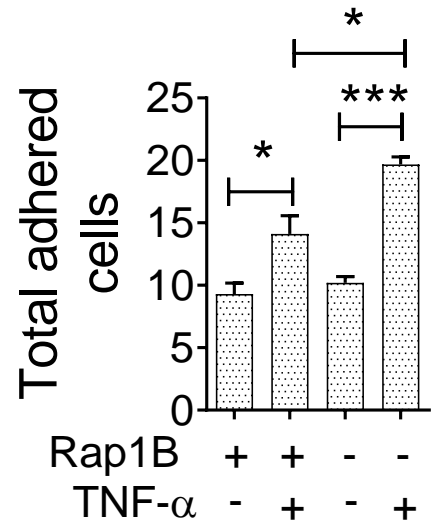

F.

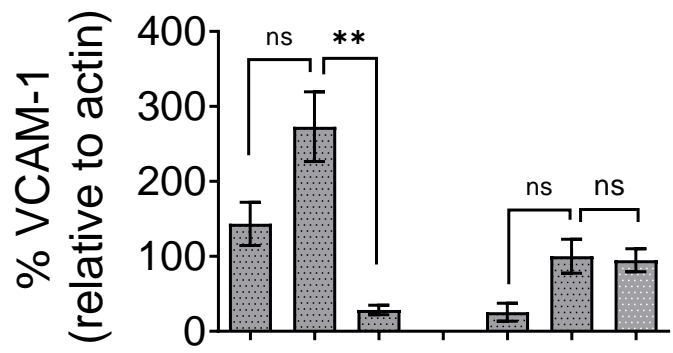

Rap1B

VCAM-1

b-Actin

Si-control +++

Si-Rap1B - - - + + +

TNF- $\alpha-++-++$

VEGF
Figure 5. Endothelial Rap1B restricts proinflammatory CAM expression, mediates VEGF

signaling. (A) Top: Densitometry of TNF $\alpha$-induced VCAM-1 expression, normalized to actin, in siControlor siRap1B- transfected HUVECs. Bottom: representative Western blot. Original images are available in Figure 5-source data 1 file. $(\mathbf{B}, \mathbf{C})$ VCAM-1 expression in tumor ECs (CD31 ${ }^{+}$cells): representative flow cytometry histogram (B) and median fluorescence intensity (MFI) (C). $n \geq 5$ mice per group, (D, E) EC-Rap1B deficiency leads to increased leukocyte adhesion in vitro. Representative image (D) and quantification (E) of CalceinAM-labeled Jurkat cells adhering to siRap1B and siControl ECs following TNF- $\alpha$ treatment 12 hours. Adhesion efficiency is expressed as Jurkat cells bound $/ 10,000$ plated. (F) VEGF treatment inhibits TNF- $\alpha$-induced CAM expression in siControl but not in siRap1B ECs. Densitometry (top) and representative Western blot (bottom) are shown. Original images are available in Figure 5source data 2 file. Data shown are mean \pm S.E.M. $*, \mathrm{P}<0.05, * *, \mathrm{P}<$ $0.01, * * *, P<0.001$, Panels $A, E, F$ : one-way ANOVA followed by

Tukey's multiple comparisons test. Panel C: Student's t-test. Data and statistical outputs are available in Figure 5-source data 3 file. 

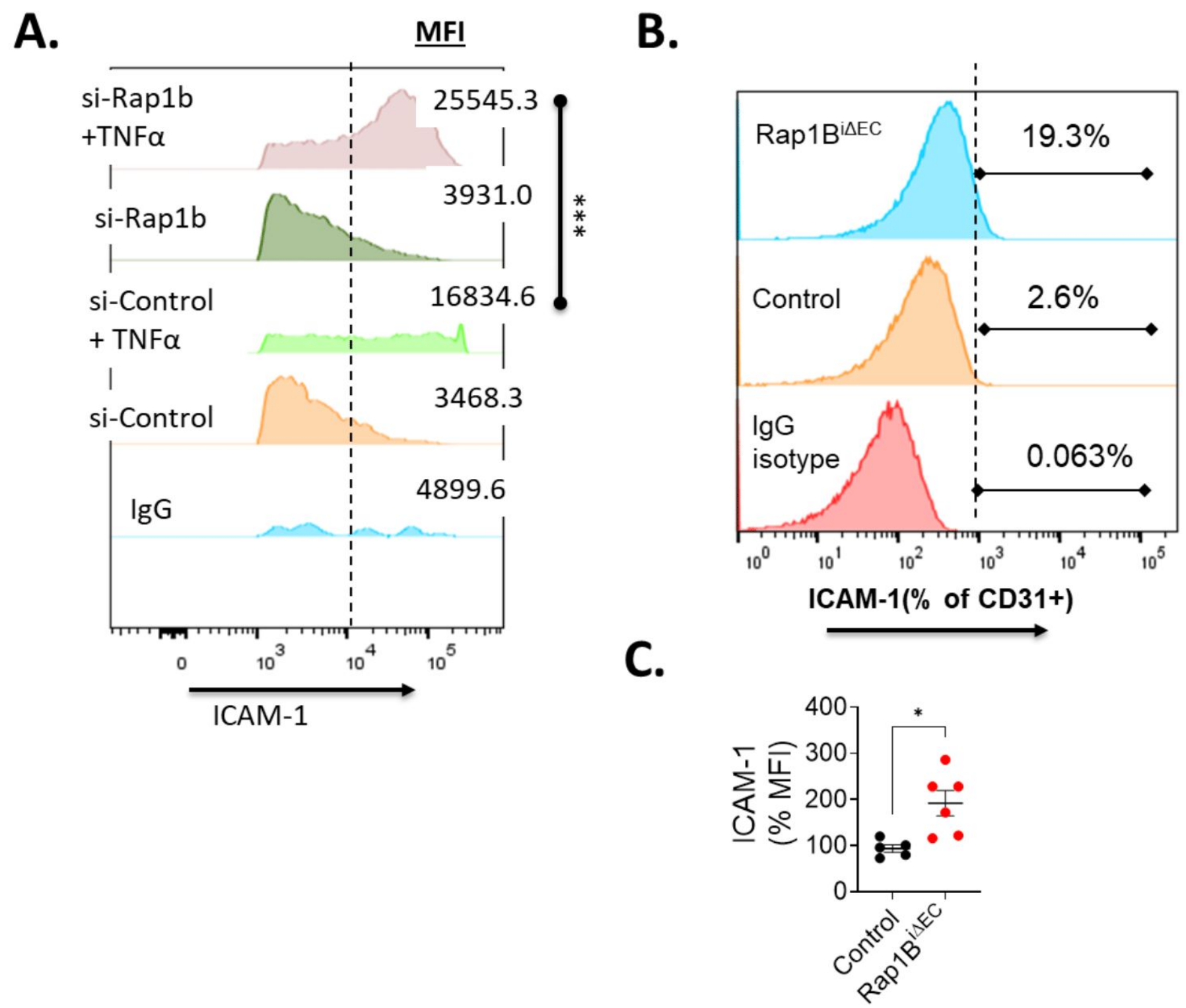

Figure 5 - figure supplement 1. Elevated ICAM-1 surface expression in Rap1B-deficient tumor ECs and HUVECs. (A) Flow cytometric analysis of ICAM-1 expression on siRap1B and siControl HUVEC cells. (B) Flow cytometric analysis of ICAM-1 expression on tumor ECs from Rap1B ${ }^{\mathrm{i} \triangle \mathrm{EC}}$ and control mice: representative flow cytometry histogram and median fluorescence intensity (MFI) plot (C). Data are presented as the mean \pm S.E.M. ${ }^{* *}, \mathrm{P}<0.01$, Student's t test. Data and statistical outputs are available in Figure 5 - figure supplement 1source data 1 file. 


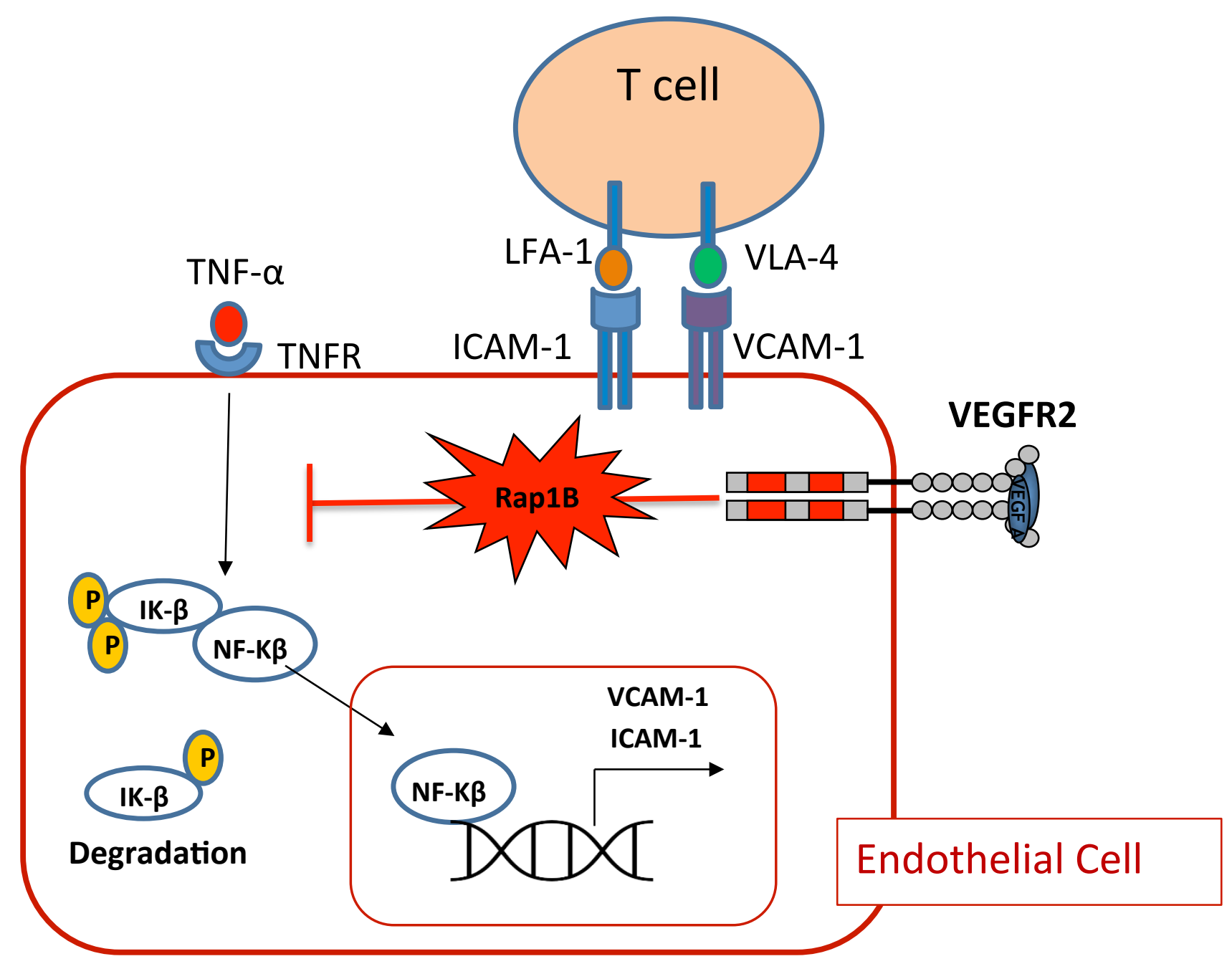

Figure 6. Endothelial Rap1B conveys VEGF suppression of immune reactivity - proposed mechanism. Under normal conditions Rap1 suppresses cytokine-induced CAM expression, limiting T-cell adhesion and recruitment. In proangiogenic conditions of TME, VEGF signaling, mediated by Rap1B, suppresses this endothelial immune response. 